\title{
Enhanced solid-state stability of amorphous ibrutinib formulations prepared by hot-melt extrusion
}

\author{
Marta F.Simões ${ }^{\mathrm{a}, \mathrm{b}}$, Bernardo A. Nogueira ${ }^{\mathrm{c}}$, Andreia M. Tabanez ${ }^{\mathrm{c}}$, Rui Fausto ${ }^{\mathrm{c}}$, Rui M.A. Pinto ${ }^{\mathrm{a}}$, \\ Sérgio Simões ${ }^{\mathrm{a}, \mathrm{b}, *}$ \\ ${ }^{a}$ Bluepharma - Indústria Farmacêutica, São Martinho do Bispo, 3045-016 Coimbra, Portugal \\ ${ }^{\mathrm{b}}$ Faculty of Pharmacy, University of Coimbra, Azinhaga de Santa Comba, 3000-548 Coimbra, Portugal \\ c Department of Chemistry, University of Coimbra, Rua Larga, 3004-535 Coimbra, Portugal
}

\section{A R T I C L E I N F O}

\section{Keywords}

Hot-melt extrusion

Amorphous solid dispersions

Ibrutinib

Polymers

Multivariate statistics

Principal components analysis

\begin{abstract}
A B S T R A C T
One of the applications of Hot-Melt Extrusion (HME) is the stabilization of amorphous drugs through its incorporation into polymeric blends in the form of Amorphous Solid Dispersions (ASDs). In this study, HME was applied to solve a real problem in the development of an ibrutinib product, stabilizing the amorphous form. A systematic approach was followed by combining theoretical calculations, high-throughput screening (HTS) focused on physical stability and Principal Components Analysis (PCA). The HTS enabled the evaluation of 33 formulations for physical stability and the PCA was key to select four promising systems. The low relevance of drug loading on the drug crystallization supported the HME tests with a very high drug load of $50 \%$. Milled extrudates were characterized and demonstrated to be fully amorphous. The thermal analysis detected a glass transition temperature much higher than the predicted values. Along with several weak intermolecular interactions detected in Raman spectroscopy, a dipolar interaction involving the $\alpha, \beta$ unsaturated ketone was also noticed. The additive effect of these intermolecular interactions changed markedly the performance of the ASDs. The physical strength of the prepared systems was corroborated by stability studies until 6 months at long-term and accelerated conditions.
\end{abstract}

\section{Introduction}

The poor water solubility of Biopharmaceutical Classification System (BCS) class II and IV molecules are the rate-limiting steps for absorption, which generally leads to low bioavailability (BA) and to their failure as therapeutic agents (Ghadi and Dand, 2017; Gupta et al., 2013). The amorphization of crystalline drugs is often seen as a solution to this problem, due to the enhanced apparent solubility caused by the disruption of the crystal lattice and its high energy state (Novakovic et al., 2018; Skrdla et al., 2019; Tran et al., 2019). Although these forms exhibit an increased rate of dissolution due to high thermodynamic activity, they have also a potential to revert to the more stable crystalline form (Karagianni et al., 2018; Lin et al., 2018). This is, in fact, the main issue associated with the amorphous state: the physical instability on aging in the form of phase separa- tion and recrystallization, which can eventually affect the dissolution (Becker et al., 2015; Gao and Shi, 2012; Sarode et al., 2013) and lead to the therapy failure. This justifies at least partially, why there are only a few amorphous drugs and formulations in the market (Lu et al., 2014; Stankovic et al., 2015). Thus, improved strategies for the stabilization of amorphous compounds in pharmaceutical development are still needed.

Hot-melt extrusion (HME) has been revealed as a successful technology for a large spectrum of applications in the pharmaceutical industry. One of the most recently reported applications of HME is the stabilization of amorphous drugs through its incorporation into polymer blends in the form of Amorphous Solid Dispersions (ASDs) (Repka et al., 2018). In spite of the promising performance of HME to enhance the physical stability of amorphous compounds, there are only a few studies reporting this application (Lakshman et al., 2008; Miller et al., 2007). Solid dispersions are systems where one component is dis-

Abbreviations: ASD, Amorphous Solid Dispersions; BA, Bioavailability; BCS, Biopharmaceutical Classification System; DS, drug substance; HTS, High-Throughput Screening; HME,

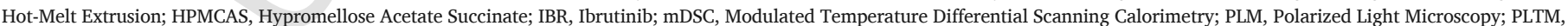

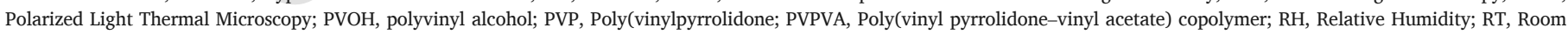

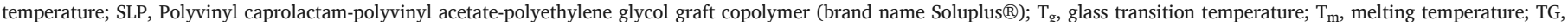
Thermogravimetry; XRPD, X-Ray Powder Diffraction; PEG6000, Polyethylene glycol grade 6000; P407, Poloxamer grade 407 micro. * Corresponding author at: Bluepharma - Indústria Farmacêutica, São Martinho do Bispo, 3045-016 Coimbra, Portugal.

E-mail address: ssimoes@ci.uc.pt (S. Simões) 
persed in a carrier (usually polymeric), and where the whole system is solid (Becker et al., 2015; Gao and Shi, 2012; Lu et al., 2014; Repka et al., 2012; Sarode et al., 2013). These systems are able to increase the physical stability of drugs through fundamentally two main approaches, as reviewed by Janssens and Mooter (Janssens and Van den Mooter, 2009) and by Baghel and colleagues (Baghel et al., 2016a). In one, polymeric carriers with high glass transition temperatures $\left(\mathrm{T}_{\mathrm{g}}\right)$ can kinetically stabilize amorphous systems by reducing molecular mobility and thus "freezing" the amorphous drug in a metastable state. The other is related to intermolecular bonds, which decrease the molecular mobility of the compound within the polymeric matrix and provide stability to the composition (Janssens and Van den Mooter, 2009; Repka et al., 2018), through the decrease of the overall thermodynamic energy. These interactions are weak, as H-bonding, van der Waals, electrostatic, ionic, or hydrophobic, but enough to stabilize ASDs.

Preliminary formulation tests with the amorphous form of ibrutinib, hereafter known as IBR, failed to demonstrate physical stability and recrystallized only after 1 month of stability at $40{ }^{\circ} \mathrm{C} / 75 \% \mathrm{RH}$. Therefore, there was the need to physically stabilize this drug and, as part of our ongoing program where HME is applied to drug product development (Simões et al., 2019; Simoes et al., 2019), a new formulation strategy was pursued, where polymers were combined with this compound by HME. A very recent study was published by Xu and colleagues (Shi et al., 2019) reporting enhanced solubility and physical stability of a coamorphous solid form of IBR and saccharin. However, as there is no guidance available for coamorphous forms to date, and even the co-crystals are still under implementation in pharmaceutical R\&D units, a polymeric formulation strategy would be preferred to mitigate risks and increase the chance of getting to patients (Sathisaran and Dalvi, 2018). To our knowledge, there is no other published strategy to enhance the physical stability of amorphous IBR.

IBR (Fig. 1) is chemically designated as 1-[(3R)-3-[4-amino-3-(4-phenoxyphenyl)-1H-pyrazolo[3,4-d]pyrimidin-1-yl]-1-piperidinyl]-2-propen-1-one, and is an inhibitor of Bruton's tyrosine kinase through the formation of a covalent bond with a cysteine residue in the active site, relevant in B cells. It is available in the market under the brand name Imbruvica ${ }^{\circledR}$, both in Europe and the USA by Janssen, for the treatment of B cell diseases, such as Mantle Cell Lymphoma, Chronic Lymphocytic Leukemia/Small Lymphocytic Lymphoma, Waldenström's Macroglobulinemia, Marginal Zone Lymphoma, and Chronic Graft versus Host Disease (Pharmacyclics \& LLC, Revision: 08/2018). A summary of the physicochemical characteristics of IBR is presented in Table 1.

Our study initiated by thermal characterization of amorphous IBR to assess the viability of the proposed strategy. A comprehensive thermodynamic evaluation of the drug and possible carriers to predict polymer-drug miscibility was then performed, followed by a high-throughput screening (HTS) focused on physical stability. Physical stability was evaluated by both Raman spectroscopy and polarized light microscopy (PLM). After the selection of the most promising systems, HME tests were performed and the extrudates characterized. Stability studies fo- cused on the physical stability of milled extrudates prepared by HME were carried out for 6 months.

\section{Materials and methods}

\subsection{Materials}

Amorphous and crystalline IBR were acquired from a GMP-approved drug supplier. Poly(vinyl pyrrolidone-vinyl acetate) copolymer (PVPVA or copovidone, brand name Kollidon ${ }^{\circledR}$ VA64), Poly(vinylpyrrolidone) (PVP or povidone of grade K12, brand name Kollidon ${ }^{\circledR} 12 \mathrm{PF}$ ), and Polyvinyl caprolactam-polyvinyl acetate-polyethylene glycol graft copolymer (brand name Soluplus ${ }^{\circledR}$ ) were obtained from BASF (Ludwigshafen, Germany). Hypromellose Acetate Succinate (HPMCAS grade MF, brand name AQOAT ${ }^{\circledR}$ ) was kindly donated by Shin-Etsu (Totowa, $\mathrm{NJ}$ ), and polyvinyl alcohol (PVOH, brand name Parteck ${ }^{\circledR}$ MXP) was obtained from Merck Millipore (Darmstadt, Germany). Polyethylene glycol (PEG6000) grade 6000 was acquired from Clariant (Hoechst) (Muttenz, Switzerland), and Poloxamer 407micro (P407), brand name Kolliphor ${ }^{\circledR}$ P407, was also obtained from BASF (Ludwigshafen, Germany).

\subsection{Methods}

Thermal Analysis: Modulated Temperature Differential Scanning Calorimetry (mDSC) analysis was performed in a Q100 (TA Instruments, New Castle, Delaware). Samples of 2-4 mg were weighed and placed in aluminum crimped pans. Modulated temperature mDSC analysis was performed using a heating rate of $5{ }^{\circ} \mathrm{C} / \mathrm{min}$, from $0{ }^{\circ} \mathrm{C}$ to $220{ }^{\circ} \mathrm{C}$, amplitude $\pm 0.80{ }^{\circ} \mathrm{C}$ and a period of $60 \mathrm{~s}$. Nitrogen purge gas was used with a flow rate of $50 \mathrm{~mL} / \mathrm{min}$. Calibration was performed using indium and tin. For each sample, measurements were performed at least in duplicate. Thermogravimetric (TG) analysis was performed on a TG Q500 (TA Instruments, New Castle, Delaware). Samples were placed in platinum pans and heated from $25{ }^{\circ} \mathrm{C}$ to $220{ }^{\circ} \mathrm{C}$ at $5{ }^{\circ} \mathrm{C} / \mathrm{min}$ under a nitrogen atmosphere $(60 \mathrm{~mL} / \mathrm{min})$.

Polarized Light Thermal Microscopy (PLTM): PLTM images were obtained through the combination of polarized light and wave compensators, a hot stage DSC600 (Linkam Scientific Instruments Ltd. Surrey, UK) with magnification power of 200x, attached to a Leica DMRB microscope (Leica Microsystems GmbH, Germany), and to a Sony CCD-IRIS/ RGB video camera. The evaluation of images was performed with Linkam Real-Time Video Measurement System software. Drug and HME samples were heated to $250{ }^{\circ} \mathrm{C}$ at a rate of $10^{\circ} \mathrm{C} / \mathrm{min}$ and, subsequently, let gradually cool until room temperature (RT).

Raman spectroscopy: All spectra were recorded with the Horiba LabRAM HR Evolution, coupled to a confocal Olympus microscope (HORIBA France SAS, France). Individual Raman spectra from various random points of the samples were collected and averaged. The focusing spot for this technique is around $1 \mu \mathrm{m}$, with a collection time between 5 and $60 \mathrm{~s}$. Each spectrum was collected from 5 to 50 times and averaged. The laser irradiation was performed at $633 \mathrm{~nm}$ wavelength, with a power of $17 \mathrm{~mW}$ and a $50 \times$ magnification objective was used

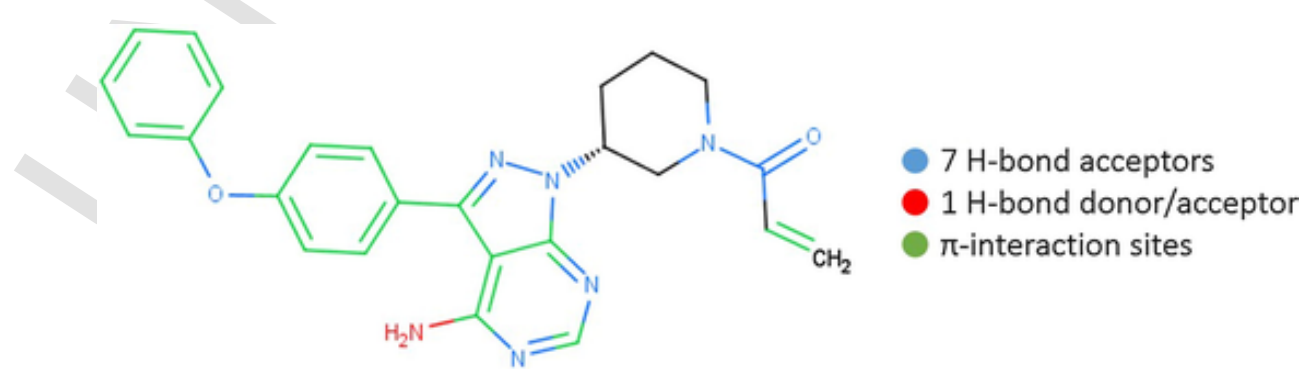

Fig. 1. Chemical structure of IBR. Potential interaction sites are highlighted. 
Table 1

Physicochemical properties of IBR (CHMP \& EMA, 2014; National Center for Biotechnology Information \& Medicine).

\begin{tabular}{ll}
\hline Characteristic & Value \\
\hline Molecular weight (MW) & $440.51 \mathrm{~g} / \mathrm{mol}$ \\
Molecular formula & $\mathrm{C}_{25} \mathrm{H}_{24} \mathrm{~N}_{6} \mathrm{O}_{2}$ \\
Melting point $\left(\mathrm{T}_{\mathrm{m}}\right.$ ) & $152.2 \pm 0.37{ }^{\circ} \mathrm{C}$ (form I, experimental data) \\
Glass transition temperature & $79.1 \pm 0.4^{\circ} \mathrm{C}$ (amorphous, experimental data) \\
$\left(\mathrm{T}_{\mathrm{g}}\right.$ ) & $99.2 \AA^{2}$ \\
Polar Surface Area & 3.97 \\
Log P & 3.74 \\
pKa (base) & $\mathrm{II}$ \\
BCS class & $0.003 \mathrm{mg} / \mathrm{mL}$ in water \\
Solubility & Practically insoluble in water \\
& Freely soluble in N,N-dimethylformamide \\
& (DMF) \\
Molar Volume & $327.5 \pm 7.0 \mathrm{~cm}{ }^{3}$ \\
\hline
\end{tabular}

to focus on every sample. The spectra were collected in a wavenumber range of $50-1800 \mathrm{~cm}^{-1}$.

Variable Temperature Raman spectroscopy: The Raman spectroscopy was carried out using the same spectrometer, irradiation source conditions and microscope described above. A $10 \times$ magnification objective, with a laser spot around $1000 \mu \mathrm{m}$ was used in order to analyze the largest possible sample area. Samples were placed in a hot stage THMS 600 (Linkam Scientific Instruments Ltd. Surrey, UK), controlled by a T95-PE Linkpad controlling unit, heated up to $170{ }^{\circ} \mathrm{C}$ at a rate of $10{ }^{\circ} \mathrm{C} / \mathrm{min}$, and gradually let to cool until RT. For IBR samples, the collection time was $10 \mathrm{~s}$ and each spectrum was collected 10 times, with a delay time of $250 \mathrm{~s}$; for HME systems, $5 \mathrm{~s}$ and 15 times, with $320 \mathrm{~s}$ of delay. Raman spectra were recorded at $10{ }^{\circ} \mathrm{C}$ intervals, in a wavenumber range of $50-1800 \mathrm{~cm}^{-1}$.

Calculation of Solubility Parameters: The thermodynamic solubility/miscibility of IBR in each polymeric carrier was assessed using Hansen solubility parameters $\delta$ (Greenhalgh et al., 1999), calculated from their chemical structures using the van Krevelen and Hoftyzer contribution group method (Van Krevelen and Te Nijenhuis, 2009). For each molecule, the energy from dispersion forces between molecules $\left(\delta_{\mathrm{d}}\right)$; the energy from dipolar intermolecular forces between molecules $\left(\delta_{\mathrm{p}}\right)$; and the energy from hydrogen bonds between molecules $\left(\delta_{\mathrm{h}}\right)$ were calculated. The total solubility parameter $\left(\delta_{\mathrm{t}}\right)$ was then determined as follows:

$\delta_{\mathrm{t}}=\sqrt{\delta_{d}^{2}+\delta_{p}^{2}+\delta_{h}^{2}}$

Prediction of $\mathrm{T}_{\mathrm{g}}$ through the Gordon-Taylor equation: The $T_{\mathrm{g}}$ of a miscible blend (drug and polymer) is given by the Gordon-Taylor equation (Eq. (2) (Gordon and Taylor, 1952)), or the simplified form by Fox (Eq. (3) (Brostow et al., 2008)):

$T g=\frac{w_{1} T g_{1}+K w_{2} T g_{2}}{w_{1}+K w_{2}}$

$\frac{1}{T g}=\frac{w_{1}}{T g_{1}}+\frac{w_{2}}{T g_{2}}$

where $T_{\mathrm{g}}, T_{\mathrm{g} 1}$, and $T_{\mathrm{g} 2}$ are the glass transition temperatures of the blend and the two different components, respectively; $w$ represents the weight fraction; $K$ is calculated from the Simha-Boyer rule, where $\rho$ indicates the true density of the component (Wang and Porter, 1995):

$K \approx \frac{\rho_{1} T g_{1}}{\rho_{2} T g_{2}}$
Design of binary system studies: Solvent evaporation technique (Simões et al., 2019) was applied to prepare small films in microscopic slides of different combinations of polymers and IBR, to narrow down on a few polymer-drug combinations. The study was designed to allow a set of screening assays in high-throughput nature, miniaturization (material sparing, small sample size), and prompt response, and encompassed 8 different polymers and drug in 5 charge levels, ranging from 10\% to $50 \%$. IBR and a panel of 8 polymers were dissolved in THF or DMF (solutions of $10 \%$ polymer + drug) and dispensed onto microscopic slides. The solvent was then evaporated. The experiments were evaluated in what concerns physical stability over 2 months, under exposure to $60{ }^{\circ} \mathrm{C}$ (oven), $40{ }^{\circ} \mathrm{C} / 75 \% \mathrm{RH}, 25{ }^{\circ} \mathrm{C} / 60 \% \mathrm{RH}$ and $\mathrm{RT}$ in the desiccator, and assessed by PLM and Raman spectroscopy.

Polarized Light Microscopy: Glass slides were examined directly for birefringence with polarized reflected light by Motic BA310MET-T equipped with Moticam 5 (both by Motic Europe, S.L.U.). Crystalline structures were evaluated qualitatively, a scale from 1 to 5 in terms of both crystals size and quantity.

Preparation of ASDs: HME was performed using a co-rotating twin-screw extruder Thermo Scientific HAAKE MiniLab II (Thermo Scientific, UK). Temperature and screw speed were optimized based on extrudate appearance, extrudability, and torque, using batch sizes of $10 \mathrm{~g}$. The powder blends were added manually in small amounts. A round die with a diameter of $2 \mathrm{~mm}$ was attached to the extruder. The screw is conical with conveying elements only. All the glassy material was cooled in a conveyor belt and ground at 20,000 rpm in IKA M20 to a fine powder. This powder was collected to glass bottles and stored in a desiccator.

X-Ray Powder Diffraction (XRPD): XRPD analysis was performed at ambient temperature using a Bruker D8 powder diffractometer (Bruker Corporation, Massachusetts, USA), in a Bragg-Brentano geometry (reflection geometry), equipped with a Ni monochromator and LYNXEYE TE energy-dispersive detector. The X-ray source used was $\mathrm{Cu} \quad \mathrm{K} \alpha^{1 / 2} \quad(1.54 \AA) \quad$ with $\quad$ lambda $_{1}=154.056 \mathrm{pm} \quad$ and $\operatorname{lambda}_{2}=154.439 \mathrm{pm}$. Spectra were collected from scans within the range $5.0^{\circ}-35.0^{\circ}$ at $2 \theta$ with a step size of $0.02^{\circ}(2 \theta)$ and time per step of $0.5 \mathrm{~s}$.

Stability studies: ASDs were stored in closed glass bottles of $30 \mathrm{~mL}$ at defined conditions (two climatic chambers, $25{ }^{\circ} \mathrm{C} / 60 \% \mathrm{RH}$, and $40{ }^{\circ} \mathrm{C}$ / $75 \% \mathrm{RH})$ and investigated from time to time with respect to crystallization (1, 3, 6 months) by XRPD. Raman spectroscopy was also performed at 6 months of stability. To evaluate by PLM, unmilled samples were preferred.

Statistical analysis: Performed using the commercial software package JMP® 14.0 from SAS Institute, Inc.

\section{Results}

\subsection{Solid-state characterization of ibrutinib}

\subsubsection{Thermal analysis}

TG and mDSC were used to evaluate the thermal stability of amorphous IBR during a heating process (Fig. 2A). There is an endothermic event in the $15-70{ }^{\circ} \mathrm{C}$ region, probably due to the loss of volatile components, which was also detected in the TG analysis (mass loss of approximately $0.6 \%$ ). This likely represents water and residual solvents, also reported at the same level by the drug manufacturer. Moreover, the $\mathrm{T}_{\mathrm{g}}$ of amorphous IBR was detected as $79.1 \pm 0.4{ }^{\circ} \mathrm{C}$, as observed in the reversing heat flow curve. An exothermic event in the region $100-175^{\circ} \mathrm{C}$ is related to a solid-solid transition from the amorphous to a crystalline phase, as no loss of mass was detected in the TG analysis. No other significant enthalpy changes are visible in the studied range of temperature and, therefore, no degradation of amorphous IBR was observed in the mDSC or in the TG analysis. IBR is thermally stable 

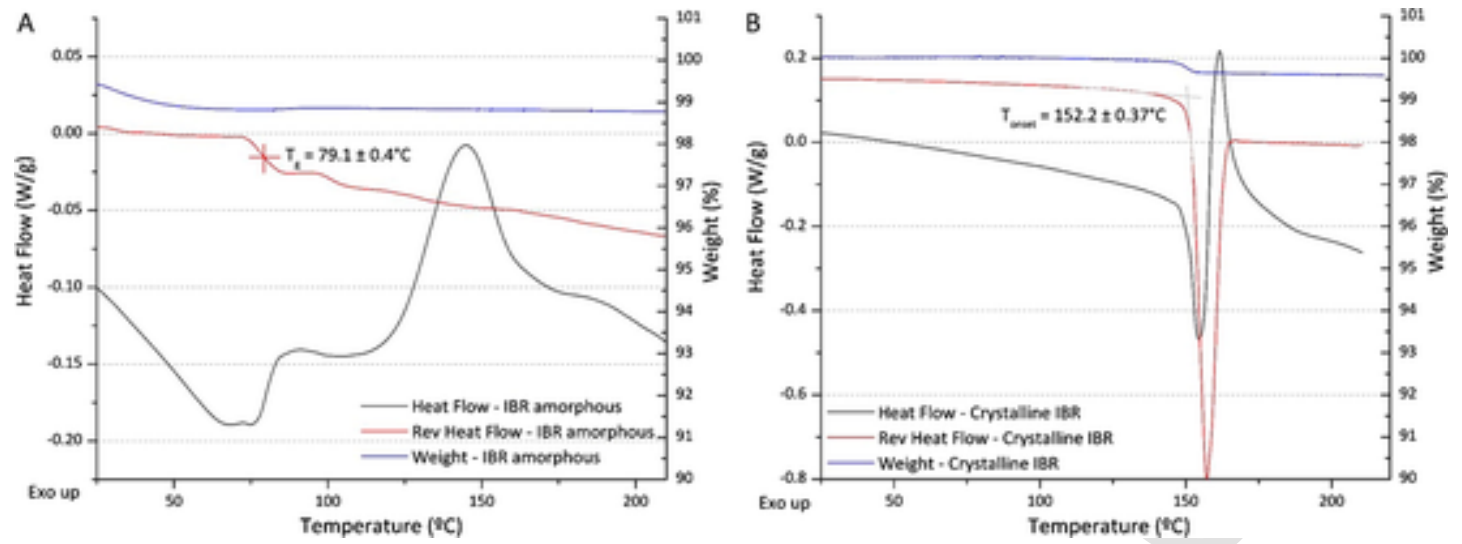

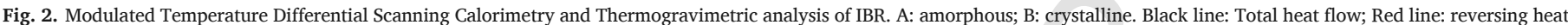

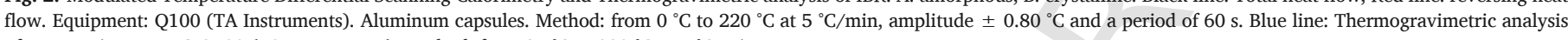
of IBR. Equipment: TG Q500 (TA Instruments). Method: from $25{ }^{\circ} \mathrm{C}$ to $220^{\circ} \mathrm{C}$ at $5{ }^{\circ} \mathrm{C} / \mathrm{min}$.

at least up to $220^{\circ} \mathrm{C}$. This working temperature is quite high and was never applied during IBR extrusion.

The crystalline IBR is characterized by an endothermic event at $152.2 \pm 0.37{ }^{\circ} \mathrm{C}$ (onset), which corresponds to the melting point, as suggested by the reverse heat flow curve (Fig. 2B). This is immediately followed by an exothermic signal between 160 and $200{ }^{\circ} \mathrm{C}$, which is related to material decomposition with a loss of mass of $0.4 \%$ reported in the TG analysis.

The amorphous drug was also characterized by PLTM, where the amorphous sample was heated up to $250{ }^{\circ} \mathrm{C}$ and then cooled gradually until RT. The results are portrayed in Fig. 3. It is possible to conclude that at $90^{\circ} \mathrm{C}$ the sample already has visible morphologic changes, compatible with a glass transition, more pronounced the higher the temperature as it evolves towards a less viscous state. The recrystallization is clearly visible from $115{ }^{\circ} \mathrm{C}$ and became more evident until $150{ }^{\circ} \mathrm{C}$. At $157^{\circ} \mathrm{C}$, the whole sample is molten, i.e. both the crystalline and the amorphous form. No changes were observed above this temperature and, after cooling, the sample returns to the initial amorphous state. These results are in agreement with the mDSC. The slight differences in the reported temperatures are essentially due to method (modulated heating rate at $5{ }^{\circ} \mathrm{C} / \mathrm{min}$ or non-modulated at $10{ }^{\circ} \mathrm{C} / \mathrm{min}$ ) and sample quantity. Moreover, mDSC experiments were performed under inert at- mosphere and hermetically sealed pan, which did not happen in the case of PLTM. Also proven by the PLTM experiment, no further relevant thermal event is detected in the amorphous IBR.

\subsubsection{Raman spectroscopy}

The Raman analysis demonstrated different spectra between the crystalline IBR and the amorphous form, with marked differences throughout the whole spectra, and in particular in the spectral regions where the most intense bands are observed, i.e., below $150 \mathrm{~cm}^{-1}$, between 700 and $800 \mathrm{~cm}^{-1}$, and between 1400 and $1650 \mathrm{~cm}^{-1}$. Relatively pronounced frequency shifts are also perceived for the bands appearing at 1471 and $1557 \mathrm{~cm}^{-1}$ in the spectrum of the crystalline material, which are observed at respectively 1476 and $1564 \mathrm{~cm}^{-1}$ in the spectrum of the amorphous material (Fig. 4). The three spectral sections where the amorphous material demonstrates the greatest divergence from the crystalline form are highlighted in the figure. These changes in the Raman spectra are caused by the destruction of the crystal lattice, as well as by the disorganized molecular orientation (Heinz et al., 2009). Raman spectroscopy is able to control the solid-state of IBR, with several regions identified and marked differences between the amorphous and crystalline forms, as also reported by Zvoníček and his group (Zvoníček et al., 2017).

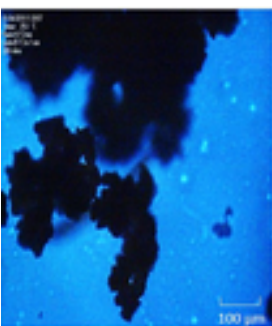

$25^{\circ} \mathrm{C}$

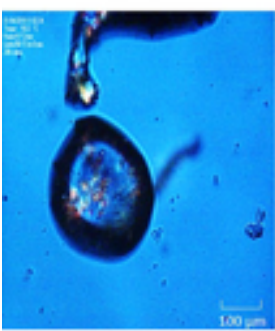

$1500^{*} \mathrm{C}$

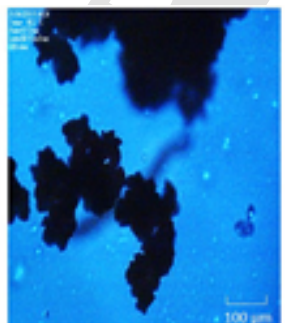

$90^{\circ} \mathrm{C}$

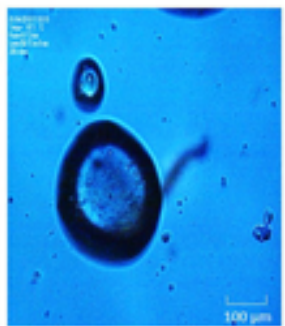

$157^{\circ} \mathrm{C}$

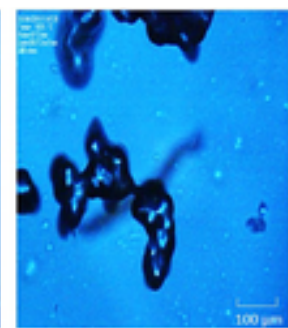

$100^{\circ} \mathrm{C}$

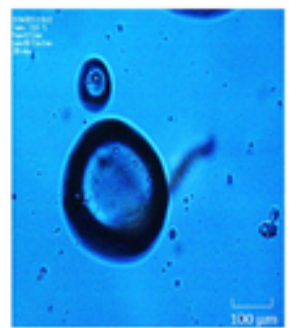

$170^{\circ} \mathrm{C}$

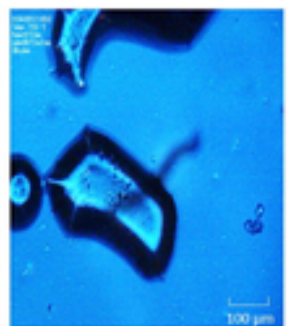

$115^{\circ} \mathrm{C}$

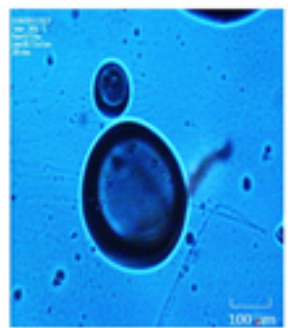

$250^{\circ} \mathrm{C}$

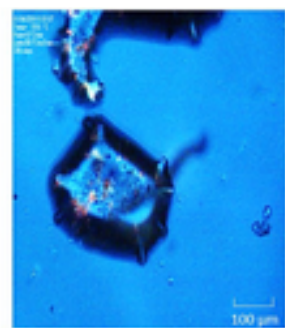

$135^{\circ} \mathrm{C}$

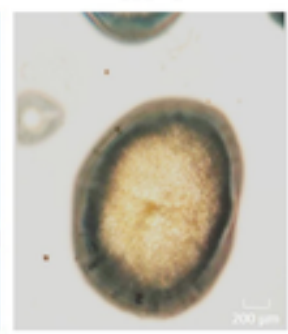

$25^{\circ} \mathrm{C}$

Fig. 3. Polarized light thermal microscopy images collected in the IBR heating process from 25 to $170{ }^{\circ} \mathrm{C}$ at a rate of $10^{\circ} \mathrm{C}$ min ${ }^{-1}$, and magnification of $200 \mathrm{x}$. 


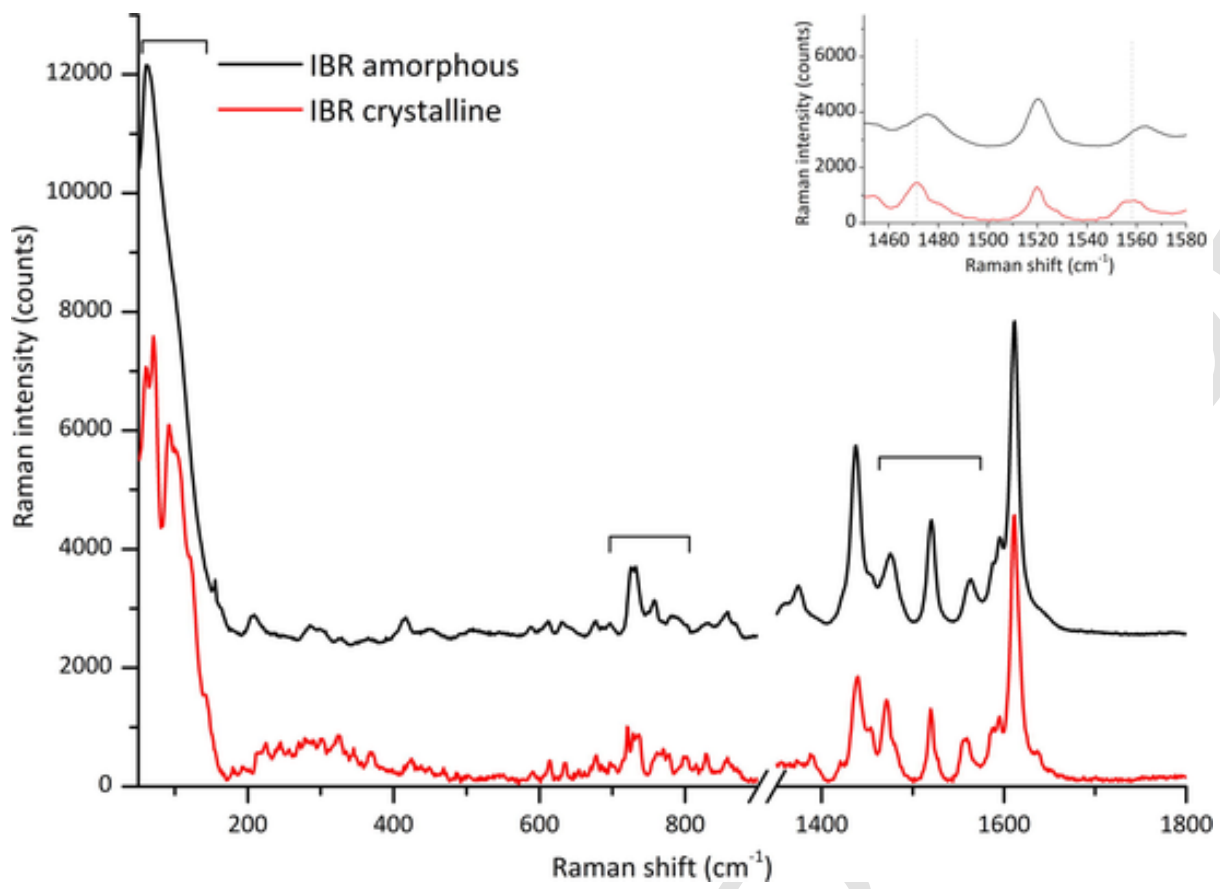

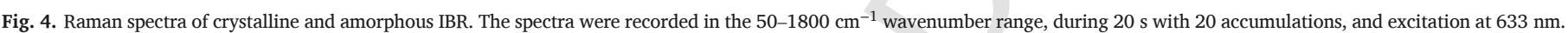

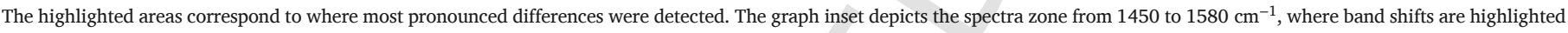
by the vertical red dashed lines (see text for discussion).

\subsubsection{Variable temperature Raman spectroscopy}

The Raman spectra were collected at different temperatures on heating to verify the potential for structural changes. IBR amorphous sample was heated up to $170{ }^{\circ} \mathrm{C}$ (well above $\mathrm{T}_{g}$ and other thermal events) and then cooled until RT. The results are portrayed in Fig. 5. Visible changes are noticed with temperature, in particular in the intensity of Raman peaks, for instance in the relative intensities of the bands at 1436 and $1476 \mathrm{~cm}^{-1}$. Moreover, shifts of the 1476 and $1564 \mathrm{~cm}^{-1}$ bands to 1469 and $1557 \mathrm{~cm}^{-1}$ respectively, are observed when heated above $120^{\circ} \mathrm{C}$, as well as changes in the area below $150 \mathrm{~cm}^{-1}$, denoting clear solid state changes compatible to conversion from amorphous to the crystalline phase. This is related to the drug recrystallization as it matches the typical bands of crystalline IBR (compare the spectra shown in Fig. 5 with the reference spectra for the amorphous and crystalline IBR presented in Fig. 4), expected due to what was already observed in the PLTM and reported in the MDSC experiment. Impor-

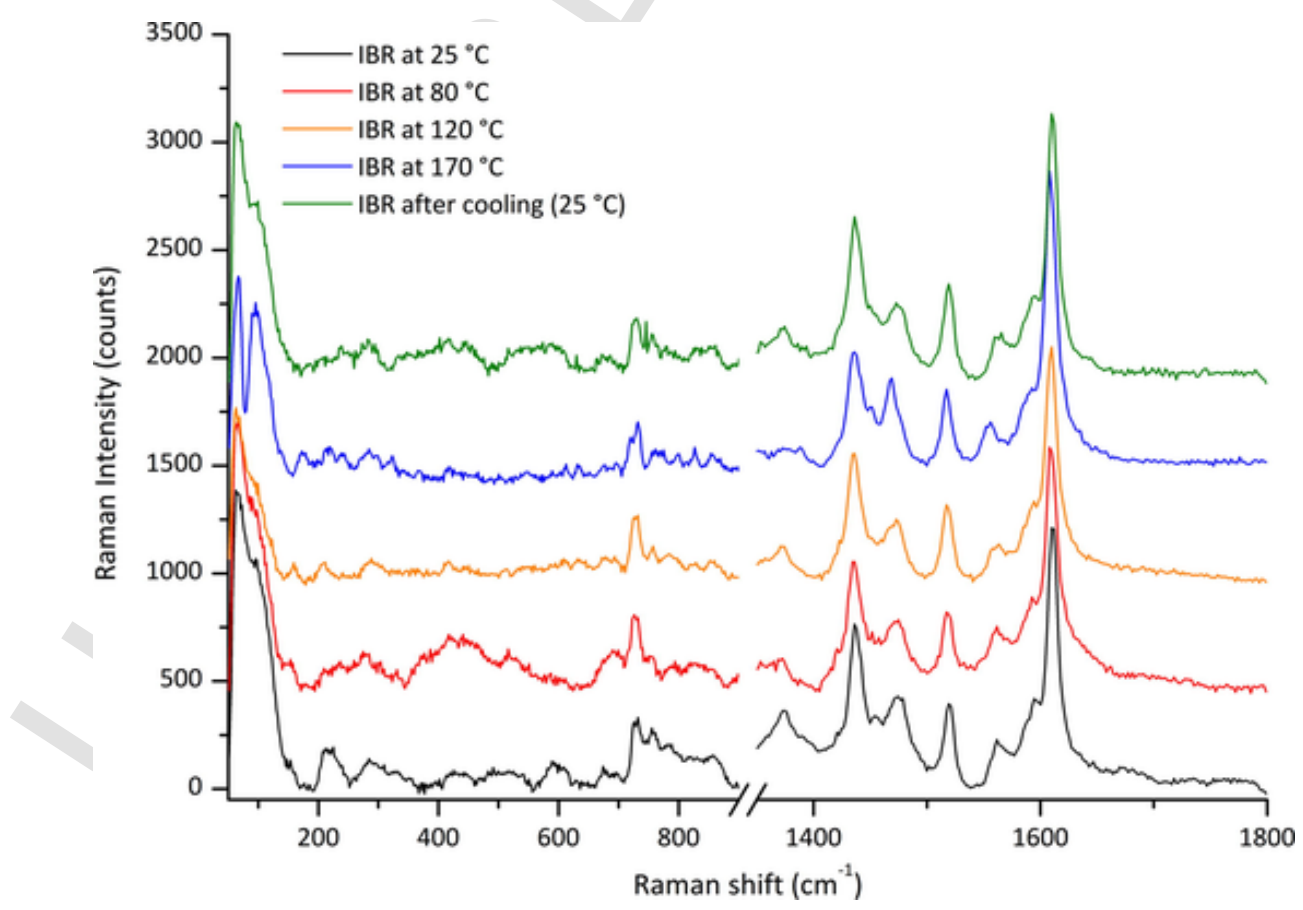

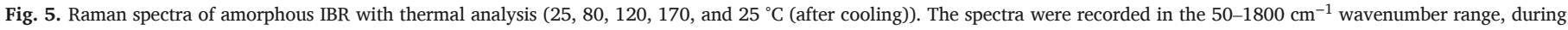
$20 \mathrm{~s}$ with 20 accumulations, and excitation at $633 \mathrm{~nm}$. 
tantly, the Raman spectra of IBR before the experiment and after re-cooling are very similar, excluding drug degradation or structural changes on heating, and supporting mDSC and PLTM conclusions.

\subsection{Prediction of drug-polymer miscibility}

Van Krevelen and Hoftyzer group contribution method (Eq. (1)) was used to calculate the Hansen solubility parameters. Eight structurally different polymers were considered at this stage. To determine the solubility parameters for SLP, which is composed of polyvinyl caprolactam: polyvinyl acetate: PEG at a ratio of 57:30:13, the average number of the three monomers was calculated. The $\delta$ for each component and the difference between the drug and each polymer $(\Delta \delta)$ are provided in Table 2 . It is known from the literature that a difference in solubility parameter of less than $7 \mathrm{MPa}^{0.5}$ indicates good miscibility, whereas if the difference is above $10 \mathrm{MPa}^{0.5}$, the system is expected to be immiscible (Forster et al., 2001; Greenhalgh et al., 1999; Lang et al., 2014; Shah et al., 2013).

IBR has a solubility parameter $\left(23.62 \mathrm{MPa}^{0.5}\right)$ closer to HPMCAS, as well as to PEG, PVPVA, and SLP, whereas HPC and PVOH had the most different results, very close or higher than the recommended cut-off limit of $7.0 \mathrm{MPa}^{0.5}$, predicting poor miscibility. According to the results in Table 2, the miscibility between IBR and each polymer is likely to follow the order: HPMCAS $>$ PVPVA $>$ PEG $>$ SLP $>$ PVP $>$ HPMC $>$ HPC $>$ PVOH. Here, $\mathrm{PVOH}$ is suggested to have the lowest solubility capacity to dissolve IBR and to produce a solid solution. However, it is important to keep in mind that the miscibility estimated by this approach is likely to be an underestimation (Lang et al., 2014; Shah et al., 2014) for complex systems involving long-range orders (such as ionic) or highly directional (as hydrogen bonding) (Baghel et al., 2016b; Pina et al., 2014; Shah et al., 2014; Trivino et al., 2019). In this work, HPMCAS, PVPVA, PEG, SLP, PVP, and HPMC were identified as the polymers with the highest potential to be miscible with IBR. PVPVA, SLP, PVP, and HPMC are usual carriers for HME immediate-release formulations, whereas PEG is preferred as a solubility-enhancer or plasticizer, and HPMCAS as a release-modifying agent or stabilizer.

\subsection{Prediction of $\mathrm{Tg}$ of the ASD through Gordon-Taylor equation}

It is well known that the $\mathrm{T}_{\mathrm{g}}$ is related to the physical stability of amorphous systems (Hancock et al., 1995; Janssens and Van den Mooter, 2009; Repka et al., 2018). Table 3 presents the results of calculated $\mathrm{T}_{\mathrm{g}}$ based on the Gordon-Taylor equation (Eq. (2)) as well as on the simplified form by Fox (Eq. (3)).

Overall, all the compositions should have neglected molecular mobility at least until $25^{\circ} \mathrm{C}$, which is the usual storage restriction

Table 2

Estimated solubility parameter of the drug and HME polymers using Hansen parameters.

\begin{tabular}{lll}
\hline Compound/Polymer & $\begin{array}{l}\text { Solubility Parameter } \delta \\
\left(\mathrm{MPa}^{0.5}\right)\end{array}$ & $\begin{array}{l}\Delta \delta=\delta_{\text {drug }}-\delta_{\mathrm{POL}} \\
\left(\mathrm{MPa}{ }^{0.5}\right)\end{array}$ \\
\hline IBR & 23.62 & - \\
PEG & 21.25 & 2.37 \\
PVP & 27.19 & 3.57 \\
PVPVA & 25.26 & 1.64 \\
SLP & 21.03 & 2.59 \\
HPMC & 27.28 & 3.66 \\
HPC & 29.71 & 6.10 \\
HPMCAS & 24.63 & 1.02 \\
PVOH & 32.52 & 8.90
\end{tabular}

$\Delta_{\text {drug }}$ solubility parameter of the drug; $\delta_{\text {POL }}$ solubility parameter of the polymer; $\Delta \delta$ solubility parameter difference between the drug and polymers.
Table 3

Prediction of $T_{g}$ of the ASD through the Gordon-Taylor and Fox equations, considering a mixture of IBR and polymer of 1:1.

\begin{tabular}{|c|c|c|c|c|}
\hline Compound/Polymer $^{a}$ & $\begin{array}{l}\mathrm{T}_{\mathrm{g}} \\
\left({ }^{\circ} \mathrm{C}\right)\end{array}$ & $\begin{array}{l}\Delta \mathrm{T}_{\mathrm{g}} \\
\left({ }^{\circ} \mathrm{C}\right)=\mathrm{Tg}_{\mathrm{DS}}-\mathrm{Tg} \\
\text { POL }\end{array}$ & $\begin{array}{l}\mathrm{T}_{\mathrm{g}}\left({ }^{\circ} \mathrm{C}\right) \text { of the } \\
\text { blend - } \\
\text { Gordon- } \\
\text { Taylor } \\
\text { equation }\end{array}$ & $\begin{array}{l}\mathrm{T}_{\mathrm{g}}\left({ }^{\circ} \mathrm{C}\right) \text { of } \\
\text { the blend } \\
\text { - Fox } \\
\text { equation }\end{array}$ \\
\hline IBR & $79.1^{c}$ & - & - & - \\
\hline PVP K12 & 90 & -10.9 & 84.2 & 84.2 \\
\hline PVPVA & 101 & -21.9 & 89.1 & 88.7 \\
\hline SLP & 70 & 9.1 & 73.9 & 74.3 \\
\hline HPMC & 178 & -98.9 & 110.5 & 109.5 \\
\hline $\mathrm{HPC}$ & 0 & 79.10 & 0.0 & 0.0 \\
\hline HPMCAS - MG & 130 & -50.9 & 98.1 & 98.4 \\
\hline
\end{tabular}

a PEG was not evaluated due to its crystalline nature. PVOH was also not considered in this evaluation due to being semi-crystalline.

b $T_{g}$ values of polymers were extracted from suppliers' technical datasheet.

c Determined experimentally by mDSC.

for pharmaceuticals, as the lowest predicted $\mathrm{T}_{\mathrm{g}}$ was around $75^{\circ} \mathrm{C}$ (in accordance with the ' $\mathrm{T}_{\mathrm{g}}-50^{\circ} \mathrm{C}$ ' rule proposed by Hancock, et al.) (Hancock et al., 1995; Yoshioka et al., 1995). It is important to keep in mind that these conclusions rely on the assumption of complete miscibility between the drug and the polymer(s) (Lang et al., 2014) and that it ignores the $\beta$-relaxation and potential intermolecular interactions. However, it is still considered guidance for determining the storage temperature and predicting the physical stability of amorphous systems.

The $\mathrm{T}_{\mathrm{g}}$ values of the amorphous polymers are very different, from 0 to $178^{\circ} \mathrm{C}$. In terms of blend $\mathrm{T}_{\mathrm{g}}$ predicted by the Gordon-Taylor equation, HPMC should provide the lowest molecular mobility, followed by HPMCAS, but very high processing temperatures are needed to extrude these pure compositions. The $\Delta \mathrm{T}_{\mathrm{g}}$ values between the drug and the polymers are quite low for PVP, SLP, and PVPVA, but not for the cellulose-based polymers. Since the $\mathrm{T}_{\mathrm{g}}$ value indicates the temperature above which the polymer chains become flexible, more interactions are expected to occur in the HME process if the components have similar $\mathrm{T}_{\mathrm{g}}$ values (Liu et al., 2013). On this ground, SLP, PVPVA, and PVP should be the most promising polymers for interacting with IBR and are considered for testing by HME. Five combinations (IBR with PVP k12, PVPVA, SLP, SLP + HPMCAS, and HPMC) were selected to proceed to the next stage, where they were evaluated experimentally in terms of physical stability to rank order performance. A binary combination with PEG was also considered as a negative control for physical stability, due to its high molecular mobility at RT.

\subsection{High-throughput screening of carriers}

Solvent-evaporation is usually applied to verify the solubility enhancement of ASDs. In this study, solvent evaporation (Simões et al., 2019) was employed to study physical stability over 2 months, assessed both by PLM and Raman spectroscopy, used as a validation of PLM observations. Small films of different combinations of polymers and IBR were prepared in microscope slides and analyzed to narrow down on a few polymer-drug combinations. High drug loads and high surface area of thin films in contact with ambient humidity lead to a lack of thermodynamic equilibrium, which promotes rapid drug crystallization and the fast failure of unstable systems. With this method, it is possible to readily select promising systems by promoting the failure of doomed compositions. The study design and detailed results may be found in the Supplementary Material.

In total, 33 systems were stored in 4 different conditions and evaluated over 2 months, where at least 5 evaluations per system by PLM/ 
Raman were performed. This led to a total of around 600 results to handle. To analyze this amount of data, a multivariate statistic was applied, namely Principal Components Analysis (PCA), where the level of crystallization, time and drug load (variables) were analyzed by storage condition. The aim was to compare the evolution of each binary composition against a hypothetically perfect system, where no crystallization would be seen throughout the stability time, no matter the condition it was exposed to. PCA is usually applied as a dimension-reduction technique, but in this case, a different application was considered, as it was applied as a means to measure the distance to the ideal amorphous system. The higher the distance, the worst the composition would be in what concerns physical stability. Two principal components were generated with statistical significance $(\mathrm{p}<0.0001$, calculated through the Bartlett Test), which explain almost the total results variability in the performed analysis, namely $86.1 \%$ for the storage at $60{ }^{\circ} \mathrm{C}$ (oven), $96.0 \%$ for the $40{ }^{\circ} \mathrm{C} / 75 \% \mathrm{RH}, 98.6 \%$ for $25^{\circ} \mathrm{C} / 60 \% \mathrm{RH}$ and $99.2 \%$ for the storage at RT (Table 4).

This deviation was quantified based on the Euclidean distance, which was calculated per system. Then, a weighted mean value of the distance was calculated in order to rank order performance. The weighted mean was preferred over an arithmetic one in order to lend higher importance to higher loadings. This was performed by condition, to check discrepancies in systems' behavior by temperature or humidity. Fig. 6 portrays an overview of these results.

It is clear that the storage at high temperature and humidity lead to more discriminant results, as the oven and the climatic chamber $40{ }^{\circ} \mathrm{C} / 75 \% \mathrm{RH}$ led to a generally higher distance from the perfect system. Although all the systems seem to be stable at low temperature and humidity, storage at $25{ }^{\circ} \mathrm{C} / 60 \% \mathrm{RH}$ and RT are clearly not discriminative after 2 months. PVP-based systems seem not to provide stability when exposed to high temperatures, which is expected due to increased chain mobility, whereas for PVPVA the humidity seems to be key, as the $40{ }^{\circ} \mathrm{C} / 75 \% \mathrm{RH}$ triggered higher crystallization than in the oven $\left(60{ }^{\circ} \mathrm{C}\right.$, dry - approximately $\left.8 \% \mathrm{RH}\right)$. HPMC compositions seem to be one of the least stables, probably due to the lack of intermolecular interactions (very discrepant $\mathrm{T}_{\mathrm{g}}$ from IBR, as seen in Table 3 ). In what concerns SLP-based compositions, it seems that it is an adequate polymer for physical stabilization, mainly if HPMCAS is added as a stabilizer.

Table 4

Eigenvalues table with results of the Bartlett test.

\begin{tabular}{|c|c|c|c|c|c|}
\hline Condition & Component & Eigenvalue & $\begin{array}{l}\text { Percent } \\
(\%)\end{array}$ & $\begin{array}{l}\text { Cumulative } \\
\text { Percent } \\
(\%)\end{array}$ & Prob $>$ ChiSq \\
\hline \multirow[t]{2}{*}{$60^{\circ} \mathrm{C}$ (oven) } & 1 & 124.27 & 47.0 & 86.1 & $<0.0001$ \\
\hline & 2 & 103.6 & 39.1 & & $<0.0001$ \\
\hline \multirow[t]{2}{*}{$40{ }^{\circ} \mathrm{C} / 75 \% \mathrm{RH}$} & 1 & 461.3 & 68.3 & 96.0 & $<0.0001$ \\
\hline & 2 & 186.6 & 27.6 & & $<0.0001$ \\
\hline \multirow[t]{2}{*}{$25^{\circ} \mathrm{C} / 60 \% \mathrm{RH}$} & 1 & 454.12 & 69.9 & 98.6 & $<0.0001$ \\
\hline & 2 & 186.34 & 28.7 & & $<0.0001$ \\
\hline \multirow[t]{2}{*}{ Room temperature } & 1 & 454.03 & 70.4 & 99.2 & $<0.0001$ \\
\hline & 2 & 185.5 & 28.8 & & $<0.0001$ \\
\hline
\end{tabular}

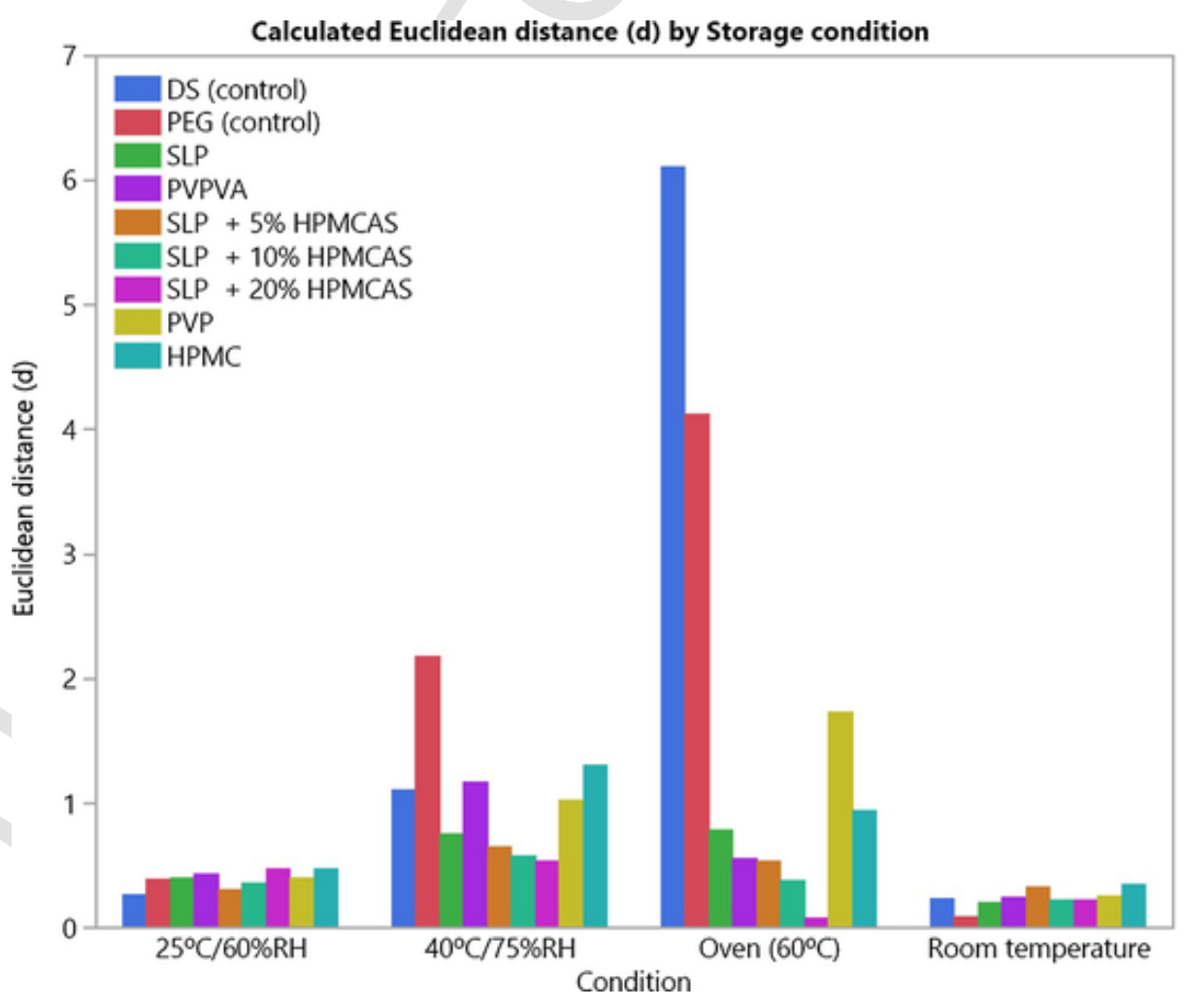

Fig. 6. Euclidean distance from the perfect system based on PCA results. 
A level of $20 \%$ of HPMCAS seems to be beneficial for IBR stabilization, mainly protecting against the effect of heat in the molecular mobility of polymers. This effect is not that clear in high humidity $\left(40{ }^{\circ} \mathrm{C} / 75 \% \mathrm{RH}\right)$, where water causes a drastic decrease of $\mathrm{T}_{g}$ of HPMCAS, leading to increased chain mobility freedom.

To conclude on the effect of individual factors such as temperature, humidity, drug load and time on crystallization, an additional multivariate statistical analysis was performed. Each polymeric composition was assessed again through PCA, in order to identify what is the underlying cause of crystallization for each system and, ultimately, what should we avoid in order to have a stable product. This may be observed by the loading plots depicting the variables (level of crystallization, time, temperature, humidity, and drug load) and the components ( 1 and 2). The details of this analysis, results and additional conclusions may be found in Supplementary material. Is was concluded that humidity is the most important factor that triggers IBR crystallization and, surprisingly, drug load seems not to be relevant for the physical stability of an ASD of IBR. Therefore, a high drug load of $50 \%$

Table 5

Formulations, extrusion parameters, appearance, and extrudability.

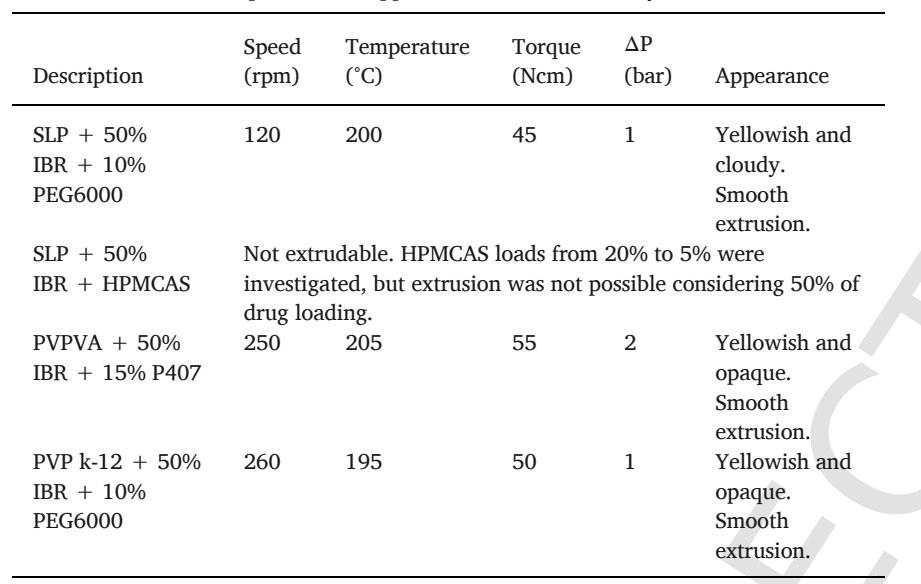

was selected to proceed to extrusion tests with the following systems: SLP, SLP $+20 \%$ HPMCAS, PVPVA, and PVP.

\subsection{HME tests}

The selected systems were subjected to HME in order to assess extrudability and physical state. The results of the extrusion of different formulations and the appearance of extrudates are detailed in Table 5. HME parameters were optimized to lead to the best appearance (clear and transparent), and to the smoothest process. High temperatures were needed to extrude these systems, which was quite unexpected due to the predicted $\mathrm{T}_{\mathrm{g}}$. Moreover, all the systems required a plasticizer, which type and amount were selected based on the manufacturability of the system. The three binary systems were easily extrudable and led to yellowish and cloudy systems. This appearance is due to the high drug loading, not completely miscible, leading to amorphous IBR suspensions.

\subsection{Characterization of the ASDs manufactured by HME}

\subsubsection{XRPD analysis}

A halo was observed in all the systems studied, which is the typical XRPD spectrum of amorphous materials (Fig. 7). In two of the systems, there are two small crystalline peaks that seem to be emerging, but they are not related to the crystalline drug. Instead, they represent the crystalline plasticizers (PEG6000 or P407), with $2 \theta$ peaks observed at 19 and $23^{\circ}$, as described in the literature (Fulop et al., 2015; Kianfar et al., 2014). Both components are known as fast re-crystallizers (Baird et al., 2010). These peaks were not detected in the SLP composition due to the complete miscibility of PEG within the formulation and in all the systems IBR was considered fully amorphous as no relevant crystalline peaks were detected.

\subsubsection{PLM characterization}

The surface of unmilled extrudates was characterized by PLM. All the systems display birefringence, but not similar to a typical crystallization pattern. Therefore, and also supported by the XRPD results,

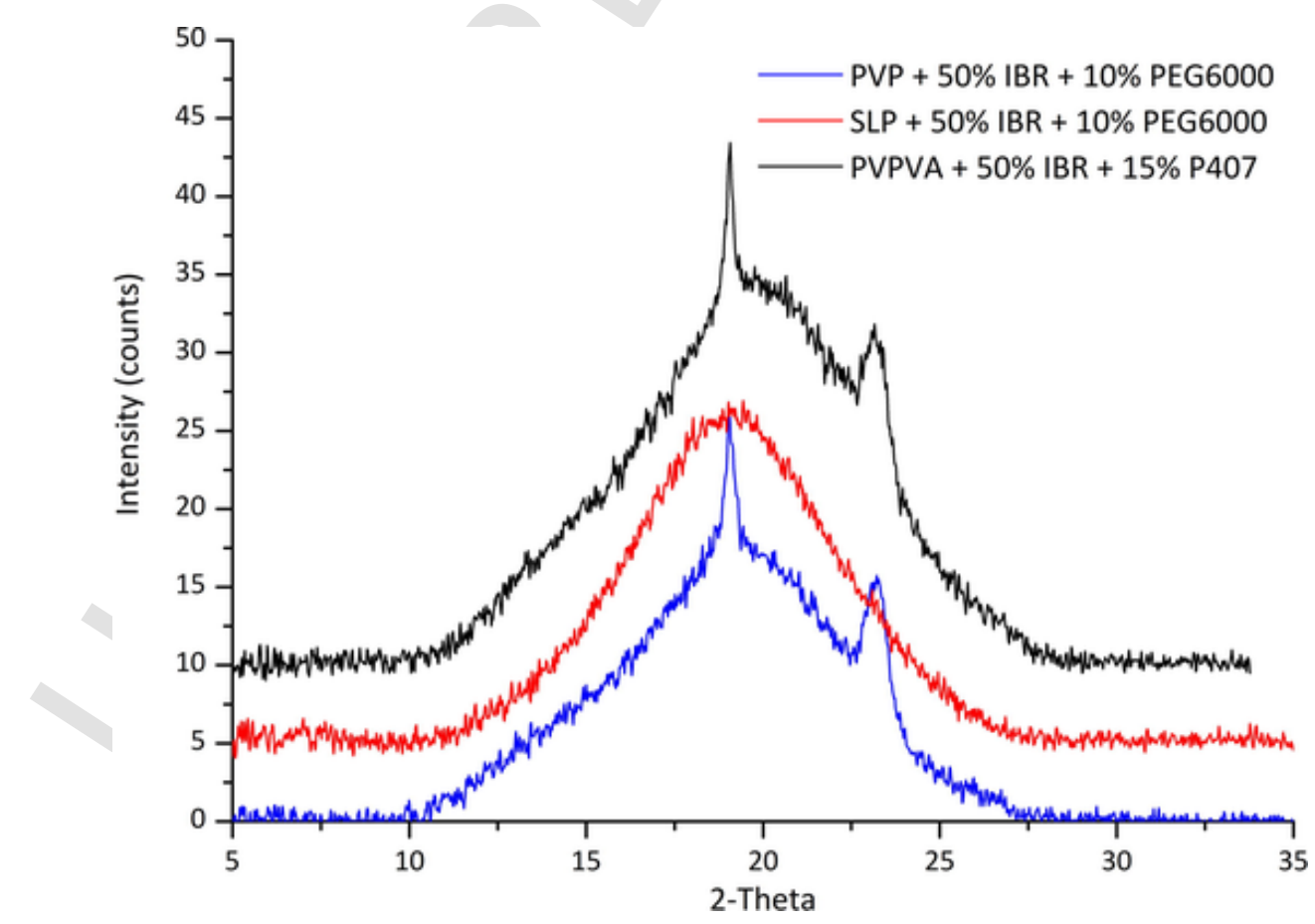

Fig. 7. Overlay of XRPD patterns of solid dispersions manufactured by HME: SLP $+50 \%$ IBR $+10 \%$ PEG6000, PVPVA $+50 \%$ IBR $+15 \%$ P407, PVP $+50 \%$ IBR $+10 \%$ PEG6000 
the observed mesh is related to the used plasticizers, which are clearly and homogenously dispersed within the matrix.

\subsubsection{Raman spectroscopy}

The Raman spectra of IBR and the three ASDs manufactured by HME, SLP $+50 \%$ IBR $+10 \%$ PEG6000, PVPVA $+50 \%$ IBR $+15 \%$ P407, and PVP $+50 \%$ IBR $+10 \%$ PEG6000, are depicted in Fig. 8 . The three sections where the different solid-state forms demonstrate the greatest divergence from the crystalline form are highlighted and were already discussed in the drug characterization section. In general and besides the observation of the characteristic Raman bands of amorphous IBR, broadening of the bands is observed in the ASDs, which corroborate with a fully amorphous dispersion of IBR.

The broader bands obtained in the ASDs may also reflect a different local environment due to a tither binding with the polymer, due to the existence of weak intermolecular interactions (Meng et al., 2015), such as Van der Waals, electrostatic or hydrophobic. Therefore, possible interactions between drug and polymers in the extrudates were also investigated, as IBR has eight H-bond acceptors, one donor, and several moieties capable of establishing $\pi$-interactions (Fig. 1) (Zvoníček et al., 2017). Changes in the Raman shift or shape of specific bands may indicate a drug-polymer interaction in these sites, as reflected in spectral features associated with $\mathrm{C}=\mathrm{O}$ stretching at $1610 \mathrm{~cm}^{-1}, \mathrm{C}$ $=\mathrm{C}$ aromatic ring chain vibrations at for instance 1475, 1587, and $2869 \mathrm{~cm}^{-1}$, and $\mathrm{C}-\mathrm{H}$ stretching modes of the alkene group at 2948 and $3066 \mathrm{~cm}^{-1}$.

In fact, there are slight shifts in the position of specific peaks, as the $858 \mathrm{~cm}^{-1}$ shifted to $843 \mathrm{~cm}^{-1}$, the $1254 \mathrm{~cm}^{-1}$ to $1260 \mathrm{~cm}^{-1}$, or the $1308 \mathrm{~cm}^{-1}$ moved to $1305 \mathrm{~cm}^{-1}$, common to the three ASDs (Fig. 9A). These may represent the formation of weak intermolecular interactions affecting the two aromatic rings, through Van der Waals or $\pi$ interactions. Moreover, a decrease in the intensity of some bands was noticed between 1150 and $1650 \mathrm{~cm}^{-1}$, specifically in the case of the band observed at $1164 \mathrm{~cm}^{-1}$, assigned to the asymmetric stretching of the ether group, $1254 \mathrm{~cm}^{-1}$, due to $\mathrm{C}-\mathrm{N}$ stretching modes, 1437 and $1520 \mathrm{~cm}^{-1}$, related to $\mathrm{C}=\mathrm{C}$ vibrations (aliphatic and aromatic),

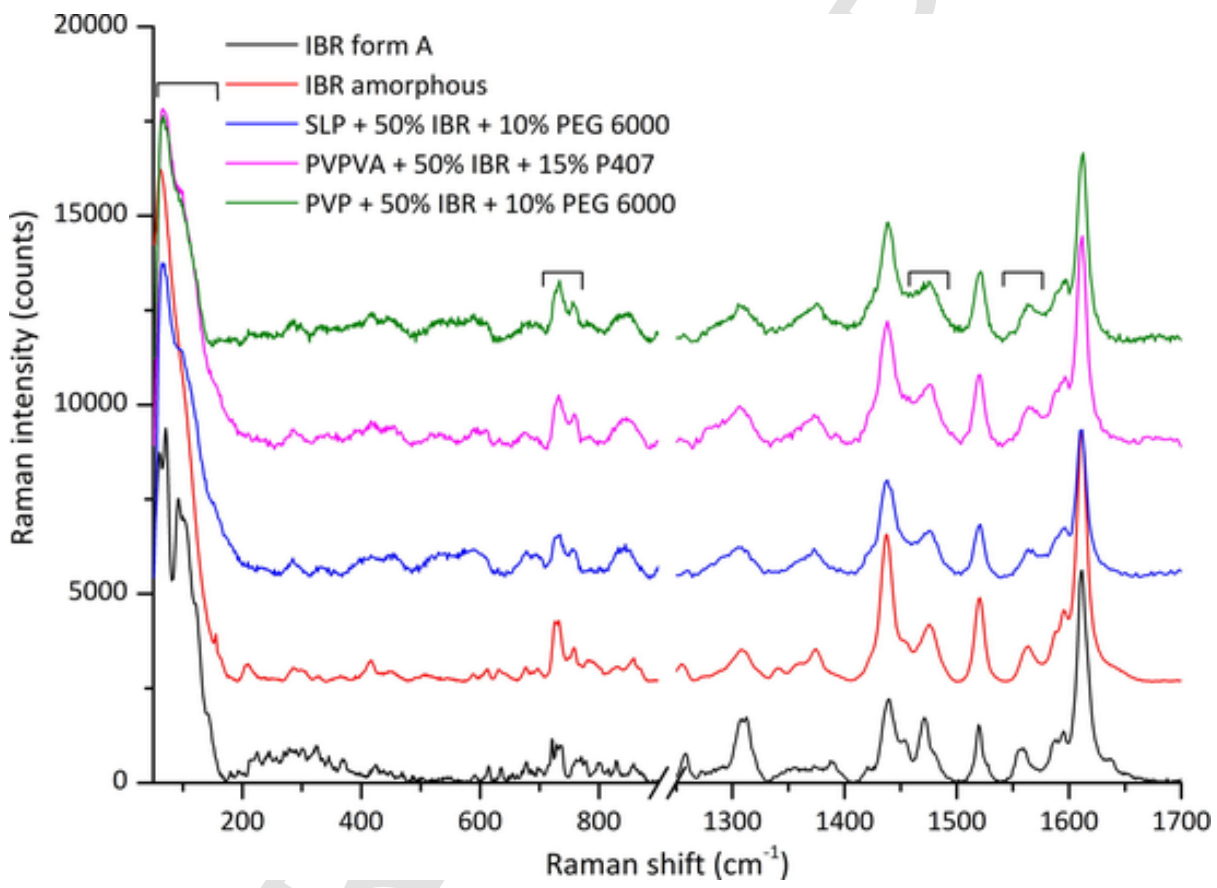

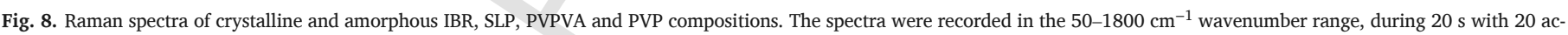

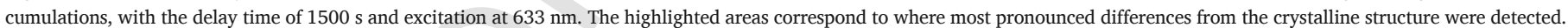
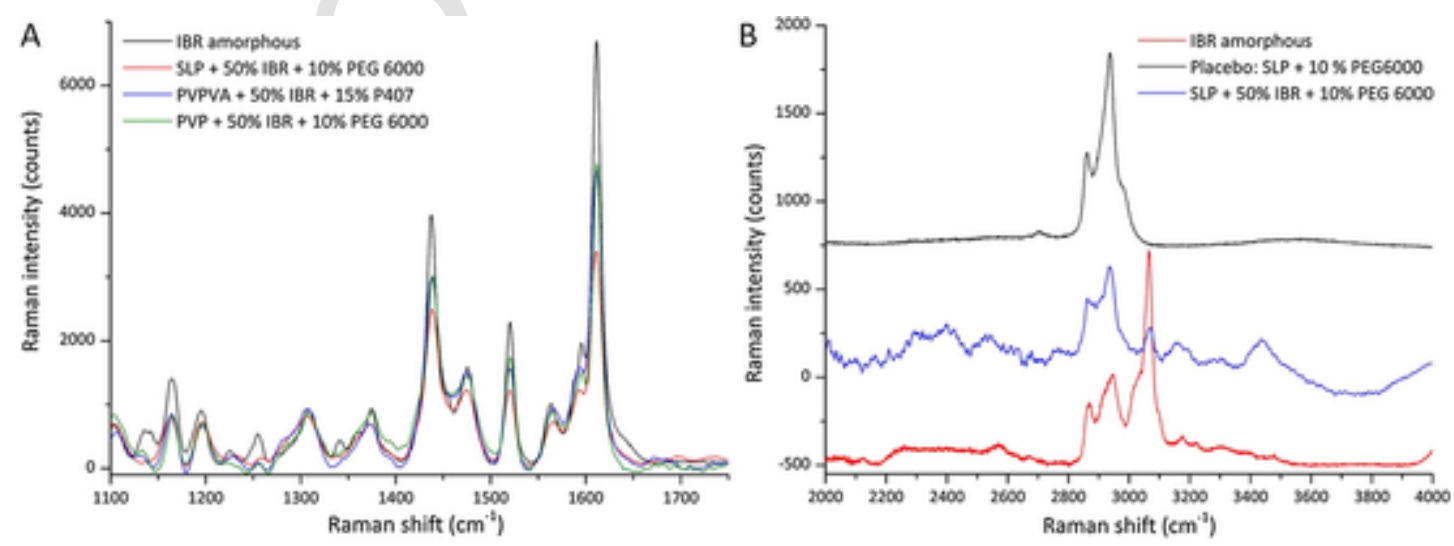

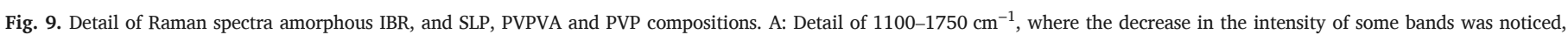

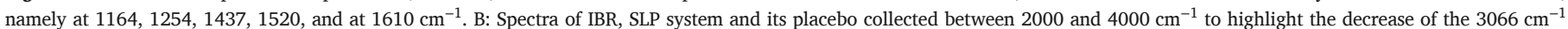
peak in the system prepared by HME. 
and $1610 \mathrm{~cm}^{-1}$, assigned to the stretching of the $\mathrm{C}=\mathrm{O}$ group (Fig. 9A) (Zvoníček et al., 2018). These changes may also be related to the involvement of these molecular fragments in new Van der Waals or $\pi$ interactions in the formulations. To investigate other possible interactions, Raman spectra until $4000 \mathrm{~cm}^{-1}$ of a representative composition was collected (SLP), and is depicted in Fig. 9B. The most notable change is also a drastic decrease of the $3066 \mathrm{~cm}^{-1}$ peak, which is attributed to the $\mathrm{C}-$ $\mathrm{H}$ stretching of the vinylic hydrogens. These findings suggest a dipolar interaction with the $\alpha, \beta$ unsaturated ketone of IBR, stabilized by electronic resonance, which decreases the $\pi$ character of the terminal $\mathrm{C}=$ $\mathrm{C}$ bond. This is corroborated by the simultaneous decrease of the frequency of the $1610 \mathrm{~cm}^{-1}$ band, attributed to the $\mathrm{C}=\mathrm{O}$. Noteworthy, the primary amine bands are usually of low intensity in Raman spectra, thus the H-bond interactions likely involving this function are not easily evidenced. Along with several weak interactions pointed out, this is likely the stronger interaction identified that enhanced significantly the physical stability of IBR through the inhibition of molecular mobility, and is the major effect responsible for its surprising behavior on extrusion.

\subsection{4. mDSC analysis}

mDSC profiles of pure polymers and solid dispersions are depicted in Fig. 10 (only reversing heat flow curves are represented, to simplify). PEG6000 and P407 were again detected as crystalline in the three systems, as an endothermic event is observed in the mDSC profile at the typical melting range of these materials $\left(40-60{ }^{\circ} \mathrm{C}\right)$. The $\mathrm{T}_{\mathrm{g}} \mathrm{s}$

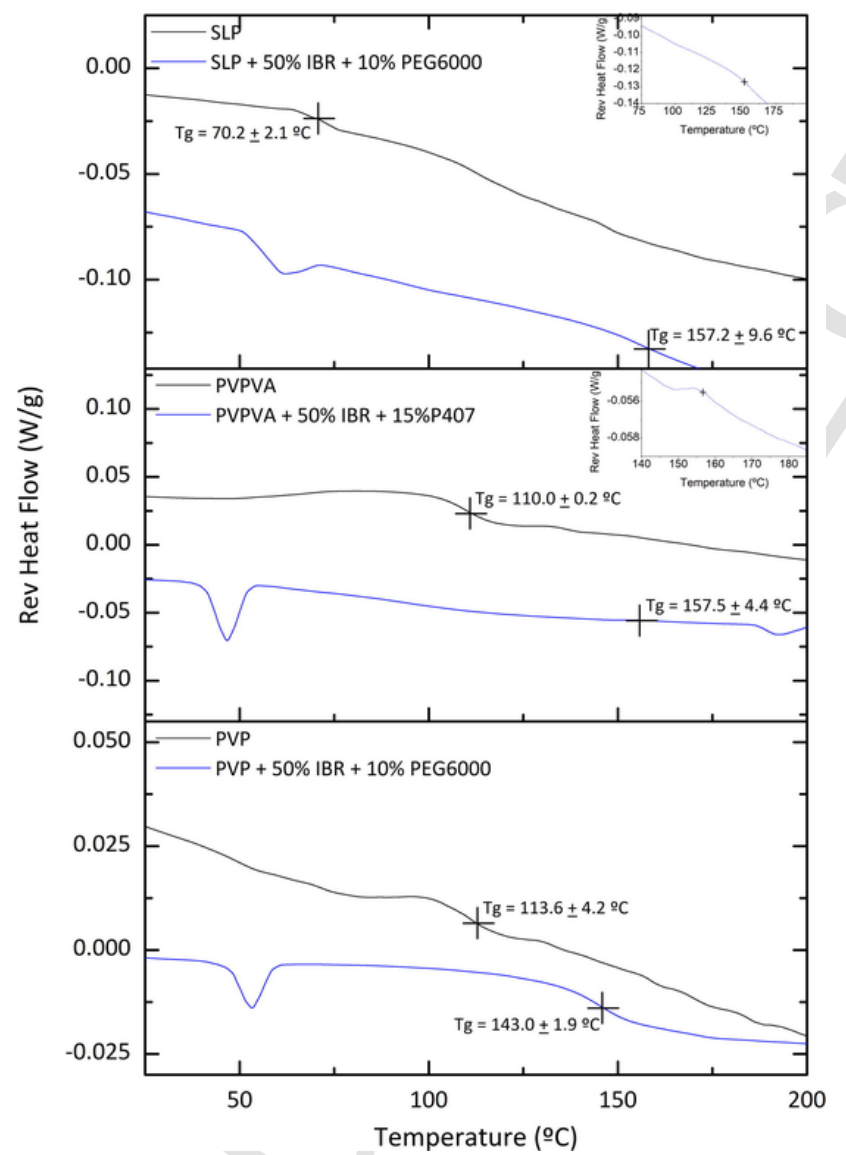

Fig. 10. Modulated Temperature Differential Scanning Calorimetry profiles for pure polymer and milled extrudates of SLP $+50 \%$ IBR $+10 \%$ PEG6000; PVPVA $+50 \%$ IBR + 15\% P407; PVP k12 + 50\% IBR + 10\% PEG6000. Method: From $0{ }^{\circ} \mathrm{C}$ to $220{ }^{\circ} \mathrm{C}$ at $5{ }^{\circ} \mathrm{C} / \mathrm{min}$, amplitude $\pm 0.80{ }^{\circ} \mathrm{C}$ and a period of $60 \mathrm{~s}$. Blue lines: solid dispersions; Black lines: pure polymer. Details of glass transition detected for the SLP and PVPVA systems are depicted as insets. were detected, both for the polymers and the solid dispersions. However, in the ASDs they are very weak, hardly detected and they were not consistent in all measurements. This is also an indication that HME samples may be characterized as between amorphous dispersions and solid solutions, where each IBR molecule is completely dispersed and embedded in the polymer, with some minor dispersed amorphous clusters. In addition, no indication of drug degradation was detected in any of the three IBR compositions.

mDSC results are in line with the observations from the PLM: the drug is dispersed within the polymer, and the plasticizer is at least partially crystalline. Another important conclusion from these measurements comes from the comparison of the theoretical $\mathrm{T}_{\mathrm{g}}$ with the experimental values. As observed in Table 6 , the experimental glass transitions are well above the predicted values, with an increment of $83^{\circ} \mathrm{C}$ for the SLP system, $65{ }^{\circ} \mathrm{C}$ for the PVPVA composition, and $50{ }^{\circ} \mathrm{C}$ for the PVP dispersion. The high $\mathrm{T}_{\mathrm{g}}$ of these systems should be the reason for the required high extrusion temperatures, much higher than expected. In addition, the theoretical predictions lack the plasticizer contribution, as well as residual moisture, which decreases the $T_{g}$, and thereby increases the real difference between predicted and experimental values. Nevertheless, the real values are still well above the predictions, and this is another indication of very strong intermolecular interactions between the drug and the polymers.

\subsection{Stability studies}

Accelerated and long-term stability studies were carried out to validate the thermodynamic predictions. The extruded ASDs were stored in ICH climatic chambers at $25{ }^{\circ} \mathrm{C} / 60 \% \mathrm{RH}$ (long-term conditions) and at $40{ }^{\circ} \mathrm{C} / 75 \% \mathrm{RH}$ (accelerated stability study). Samples were investigated for recrystallization by XRPD and PLM imaging periodically, namely after 1,3 and 6 months of storage in these conditions. Raman spectroscopy was also performed after 6 months of storage in all samples. The results, including XRPD, and Raman, are summarized in Table 7. Additional information may be found in Supplementary Material.

The IBR drug samples crystallized right after 3 months at $40{ }^{\circ} \mathrm{C} /$ $75 \% \mathrm{RH}$, as demonstrated by XRPD, whereas at $25^{\circ} \mathrm{C} / 60 \% \mathrm{RH}$ the drug was kept in the amorphous form during the whole stability study, as observed in the Raman spectra, as well as in the XRPD diffractogram. When formulated (preliminary IBR formulation), the physical stability of IBR was lower and IBR crystallized only after one month at $40{ }^{\circ} \mathrm{C}$ / $75 \% \mathrm{RH}$, and after 6 months at $25{ }^{\circ} \mathrm{C} / 60 \% \mathrm{RH}$. This demonstrates, indeed, the need for a stabilization strategy of amorphous IBR. When included in any of the three HME systems, no recrystallization of IBR was observed whatever the storage condition was, even at $40{ }^{\circ} \mathrm{C} / 75 \% \mathrm{RH}$. The samples exhibit two identifiable XRPD peaks at 19 and $232 \theta$, but they do not match the patterns of IBR in 20. They are attributed to crystalline PEG6000 and P407, as reported (Fulop et al., 2015; Kian-

Table 6

Prediction of $\mathrm{T}_{\mathrm{g}}$ of milled extrudates through the Gordon-Taylor equation and comparison with experimental values.

\begin{tabular}{lllll}
\hline Component & $\begin{array}{l}\text { Experimental Tg } \\
\left({ }^{\circ} \mathrm{C}\right) \text { of pure } \\
\text { components }\end{array}$ & $\begin{array}{l}\text { Calculated Tg } \\
\left({ }^{\circ} \mathrm{C}\right) \text { of the } \\
\text { blend }^{\mathrm{a}}(1: 1)\end{array}$ & $\begin{array}{l}\text { Experimental Tg } \\
\left({ }^{\circ} \mathrm{C}\right) \text { of milled } \\
\text { extrudates }\end{array}$ & $\begin{array}{l}\Delta \\
\mathrm{Tg} \\
\left({ }^{\circ} \mathrm{C}\right)\end{array}$ \\
\hline IBR & $79.1 \pm 0.4$ & - & - & - \\
SLP & $70.2 \pm 2.1$ & 74.1 & $157.16 \pm 9.6$ & 83.1 \\
PVPVA & $110.0 \pm 0.2$ & 92.6 & $157.52 \pm 4.4$ & 64.9 \\
PVP K12 & $113.6 \pm 4.2$ & 93.3 & $142.97 \pm 1.9$ & 49.7 \\
\hline
\end{tabular}

a Based on the Gordon-Taylor equation, based on experimental $\mathrm{Tg}$ determination of individual components.

b Equipment: Q100 (TA Instruments). Aluminum capsules. Method: From $0{ }^{\circ} \mathrm{C}$ to $220{ }^{\circ} \mathrm{C}$ at $5{ }^{\circ} \mathrm{C} / \mathrm{min}$, amplitude $\pm 0.80{ }^{\circ} \mathrm{C}$, period of $60 \mathrm{~s}$. 
Table 7

Analytical results of extrudates of IBR amorphous drug and ASDs manufactured by HME on stability.

\begin{tabular}{|c|c|c|c|c|c|c|c|c|}
\hline \multirow[t]{2}{*}{ Formulation } & \multirow{2}{*}{$\begin{array}{l}\text { Storage } \\
\text { Time } \\
\text { points } \\
\text { (months) }\end{array}$} & \multirow{2}{*}{$\begin{array}{l}- \\
\\
0\end{array}$} & \multicolumn{2}{|c|}{$25{ }^{\circ} \mathrm{C} / 60 \% \mathrm{RH}$} & \multicolumn{4}{|c|}{$40{ }^{\circ} \mathrm{C} / 75 \% \mathrm{RH}$} \\
\hline & & & 1 & 3 & 6 & 1 & 3 & 6 \\
\hline \multirow[t]{3}{*}{ Amorphous drug } & Appearance & Loose & Loose & Loose & Loose & Lumps & Lumps & Lumps \\
\hline & XRPD & A & - & - & A & A & $\mathrm{C}$ & $\mathrm{C}$ \\
\hline & Raman & A & - & - & A & - & & A \\
\hline Preliminary IBR formulation & XRPD & A & A & A & C & C & $\mathrm{C}$ & C \\
\hline \multirow{3}{*}{$\mathrm{SLP}+50 \% \mathrm{IBR}+10 \% \mathrm{PEG} 6000$} & Appearance & Loose & Loose & Loose & Loose & Loose & Loose & Loose \\
\hline & XRPD & A & - & - & - & $\mathrm{A}^{*}$ & $\mathrm{~A}^{*}$ & $A^{*}$ \\
\hline & Raman & A & - & - & A & - & - & A \\
\hline \multirow[t]{3}{*}{ PVPVA $+50 \%$ IBR $+15 \%$ P407 } & Appearance & Loose & Loose & Loose & Loose & Loose & Loose & Loose \\
\hline & XRPD & $A^{*}$ & - & - & - & A & A & A \\
\hline & Raman & A & - & - & A & - & - & A \\
\hline \multirow[t]{3}{*}{$\mathrm{PVP}+50 \% \mathrm{IBR}+10 \%$ PEG6000 } & Appearance & Loose & Loose & Loose & Loose & Loose & Loose & Loose \\
\hline & XRPD & $A^{*}$ & & - & - & $A^{*}$ & $A^{*}$ & $A^{*}$ \\
\hline & Raman & $\mathrm{A}$ & & - & $\mathrm{A}$ & - & - & $\mathrm{A}$ \\
\hline
\end{tabular}

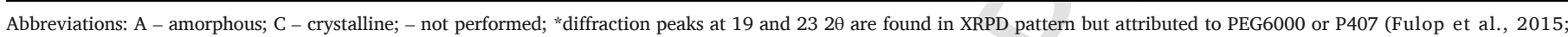
Kianfar et al., 2014).

far et al., 2014). They were used in the formulations as plasticizers, and these peaks occurred already after preparation.

The Raman spectra were initially collected and they provided support to assess the physical state of IBR during the stability tests. The Raman spectroscopy characterized all samples as amorphous, both drug and polymeric systems, at T0 and 6 months (Fig. 11). The typical amorphous IBR Raman shifts and band shapes were detected, and the residual crystallinity of IBR when exposed to $40{ }^{\circ} \mathrm{C} / 75 \% \mathrm{RH}$ was not detected. It seems that, in this case, XRPD is able to detect crys- talline traces sooner than Raman. Besides a complementary technique for structural characterization, another important contribution of Raman spectroscopy is the ability to detect chemical changes over time. For the PVPVA and PVP systems, the Raman spectra are quite similar to the amorphous drug and to T0. However, there are three newly identified bands in the SLP system when exposed to $40{ }^{\circ} \mathrm{C} / 75 \% \mathrm{RH}$, detected at 634,984 and $1731 \mathrm{~cm}^{-1}$, highlighted in Fig. 11 with *. These bands were not present neither at T0 nor at 6 months in the $25^{\circ} \mathrm{C}$ /
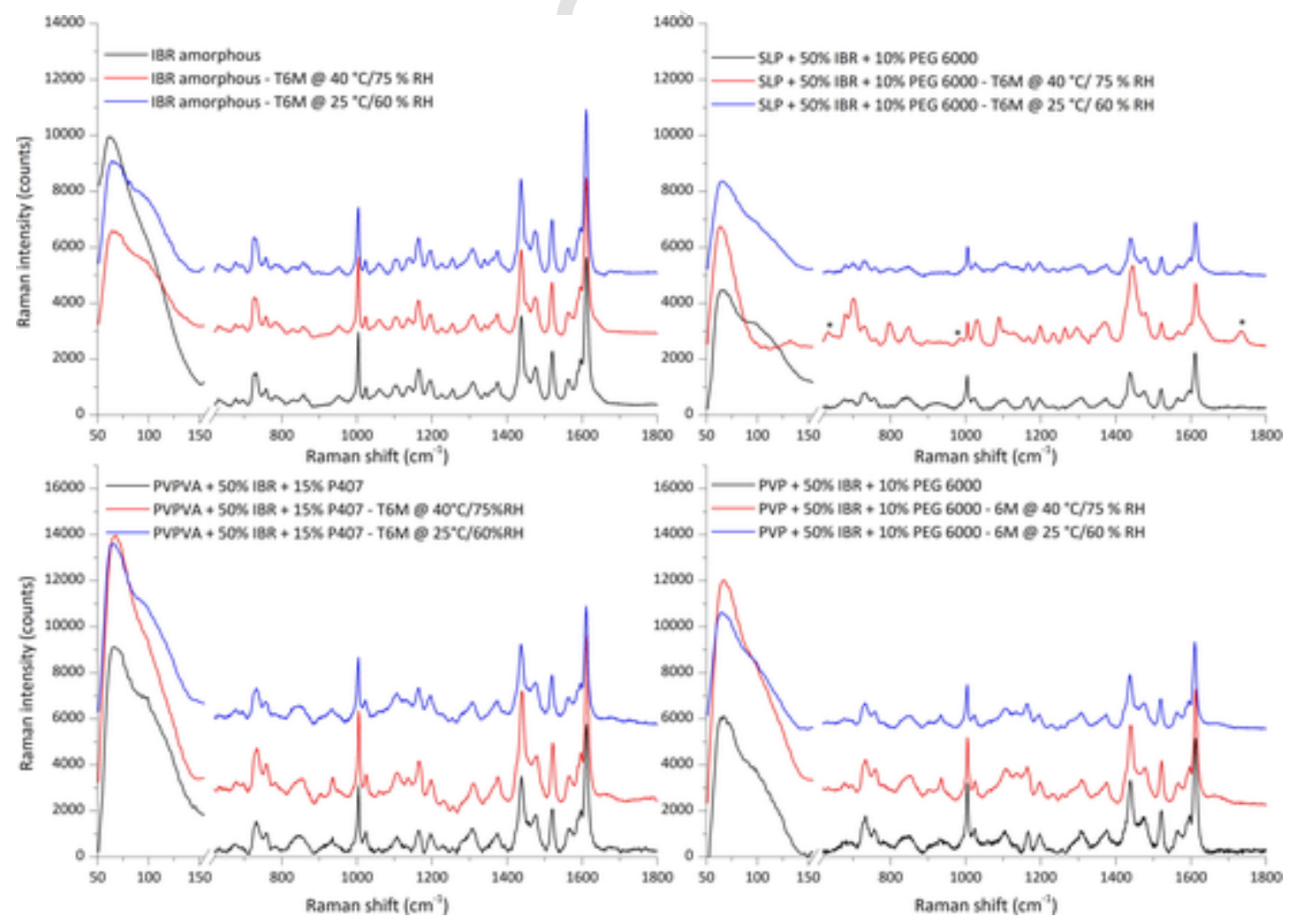

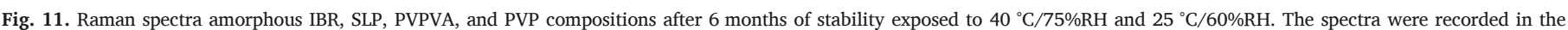

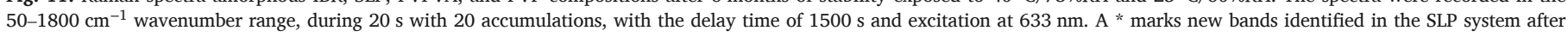
6 months of storage at $40{ }^{\circ} \mathrm{C} / 75 \% \mathrm{RH}$. 
$60 \% \mathrm{RH}$ chamber. They are attributed to the chemical degradation of the SLP system, where a storage restriction is needed.

Raman spectroscopy was also used to verify changes and intermolecular interactions over time, in stressed conditions at various humidity and temperature conditions. All the reported deviations of Raman shifts at T0 and attributed to intermolecular interactions were maintained over time, for the three systems under study. In addition, in the SLP composition, the $1437 \mathrm{~cm}^{-1}$ peak was also shifted to $1445 \mathrm{~cm}^{-1}$. This may be a reflection of the reported minor chemical degradation, but can also be attributed to $\mathrm{C}=\mathrm{C}$ vibrations, triggered by the typical moisture uptake of these systems in such high humidity conditions.

\section{Discussion}

In this study, a real technical hurdle was resolved, the thermodynamic instability of the amorphous IBR. The study initiated with a full characterization of IBR by thermal analysis coupled with Raman spectroscopy, which was essential to exclude the possibility of drug degradation with heat or other transformation that require enthalpy changes during HME processing. Then theoretical thermodynamic predictions were performed, namely miscibility based on the Hansen solubility parameters and the $\mathrm{T}_{\mathrm{g}}$ with the Gordon-Taylor equation. Selected polymers were subjected to a complete HTS focused on physical stability, where PLM was complemented with Raman spectroscopy to select the most promising systems. Multivariate statistics was key to extract useful conclusions from the HTS, namely the relevance of humidity in triggering IBR crystallization and the low importance of drug load. The latest was surprising taking into account the typical behavior of amorphous systems and the well-known correlation between thermodynamic stability and drug load.

Three systems were manufactured, all characterized as amorphous by thermal analysis, XRPD, and Raman spectroscopy. The HME process required high temperatures to process these systems, which was unexpected due to the predicted $\mathrm{T}_{\mathrm{g}}$ by the Gordon-Taylor equation. The experimental $\mathrm{T}_{\mathrm{g}} \mathrm{s}$ were determined with $\mathrm{mDSC}$, and they were well above the predicted values. In fact, it is known that this approach ignores potential intermolecular interactions, and was, indeed, an underestimation for these systems. Moreover, this was the reason for the required high extrusion temperatures and an indication of strong interactions between the drug and the polymers.

The Raman spectroscopy was used to investigate drug-polymer intermolecular interactions. There are shifts in the position of specific peaks, common to the three ASDs and probably related to a weak interaction affecting the aromatic rings of IBR, through a Van der Waals or $\pi$ interactions. Moreover, a decrease in the intensity of some bands between 1150 and $1650 \mathrm{~cm}^{-1}$ was noticed, assigned to the stretching of the ether group, $\mathrm{C}-\mathrm{N}$ stretching, $\mathrm{C}=\mathrm{C}$ vibrations, and to the stretching of the benzene groups, either caused by Van der Waals or $\pi$ interactions. Amine groups do not commonly lead to intense signals in Raman spectroscopy, which are even less intense and broader when involved in hydrogen bonds, as observed in the pure IBR amorphous. Therefore, hydrogen bond interactions were not evidenced by Raman spectroscopy. Nevertheless, the decrease of the 3066 and $1610 \mathrm{~cm}^{-1}$ peaks was attributed to a strong intermolecular dipolar interaction, involving the $\alpha, \beta$ unsaturated ketone. All these interactions between amorphous IBR and the polymers justify the surprisingly high $\mathrm{T}_{g}$ of the prepared HME systems. The additive effect of these intermolecular interactions changed brutally the performance of the ASDs, observed latter in the stability studies.

Raman spectroscopy identified three new bands in the SLP system when exposed to $40{ }^{\circ} \mathrm{C} / 75 \% \mathrm{RH}$, detected at 634,984 and $1731 \mathrm{~cm}^{-1}$ and likely attributed to chemical degradation. Although physically stable, the SLP composition should require a storage restriction to avoid impurities, and this is considered for product development from the very early. Overall, all these compositions were determined to be amor- phous until at least 6 months, both by XRPD and Raman spectroscopy, which indicated that the molecular mobility of the IBR compound in the prepared matrixes is slow enough to avoid crystallization, even when stored in accelerated conditions. It revealed the physical strength of these polymeric systems in the presence of high humidity and temperature.

\section{Conclusion}

A systematic approach for the stabilization of an amorphous IBR is reported, a drug with a high tendency for crystallization. After a thermodynamic evaluation, a preliminary experimental assessment was performed in a miniaturized and high-throughput manner. Promising systems were selected with the support of multivariate statistics, namely PCA, and three ASDs prepared by HME. They were characterized as amorphous by XRPD, mDSC, and Raman spectroscopy. It is known that the theoretical $\mathrm{T}_{\mathrm{g}}$ calculated from the Gordon-Taylor equation ignores potential intermolecular interactions, and there was indeed a drastic increase in the experimental $\mathrm{T}_{\mathrm{g}}$. This was caused by the additive effect of several interactions detected in the Raman spectra of the ASDs. These findings were confirmed through stability studies of milled extrudates until 6 months at long-term and accelerated conditions, where no IBR crystallization was detected by XRPD and Raman spectroscopy. The quite unexpected high physical stability of these systems at $40{ }^{\circ} \mathrm{C}$ / $75 \% \mathrm{RH}$ is also attributed to these intermolecular interactions.

\section{CRediT authorship contribution statement}

Marta F. Simões: Conceptualization, Methodology, Formal analysis, Investigation, Writing - original draft, Visualization. Bernardo A. Nogueira: Investigation, Formal analysis. Andreia M. Tabanez: Investigation, Formal analysis. Rui Fausto: Methodology, Formal analysis, Writing - review \& editing, Supervision. Rui M.A. Pinto: Conceptualization, Methodology, Formal analysis, Writing - review \& editing, Supervision. Sérgio Simões: Conceptualization, Methodology, Writing - review \& editing, Supervision, Resources.

\section{Declaration of Competing Interest}

The authors declare that they have no known competing financial interests or personal relationships that could have appeared to influence the work reported in this paper.

\section{Acknowledgments}

This work was supported by Bluepharma, Coimbra, Portugal, and by the Fundação para a Ciência e Tecnologia (FCT), Portugal [Ph.D. grant nr PD/BDE/135149/2017]. The Coimbra Chemistry Centre (CQC) is also supported by FCT, through the project UI0313/QUI/2013, also co-funded by FEDER/COMPETE 2020-EU. The authors also thank Profs. E. Eusébio (Department of Chemistry, University of Coimbra) and J. Canotilho (Faculty of Pharmacy, University of Coimbra) for their help with the PLTM measurements.

\section{Appendix A. Supplementary material}

Details of the high-throughput study results on physical stability (PLM), Results of PCA analysis from the HTS results per storage condition and polymeric system, Results of HME systems on stability, namely PLM, XRPD, and Raman spectroscopy.

Supplementary data to this article can be found online at https://doi. org/10.1016/j.ijpharm.2020.119156.

\section{References}

Baghel, S., Cathcart, H., O'Reilly, N.J., 2016. Polymeric amorphous solid dispersions: a review of amorphization, crystallization, stabilization, solid-state characteriza- 
tion, and aqueous solubilization of biopharmaceutical classification system class II drugs. J. Pharm. Sci. 105 (9), 2527-2544. doi:10.1016/j.xphs.2015.10.008.

Baghel, S., Cathcart, H., O'Reilly, N.J., 2016. Theoretical and experimental investigation of drug-polymer interaction and miscibility and its impact on drug supersaturation in aqueous medium. Eur. J. Pharm. Biopharm. doi:10.1016/j.ejpb.2016.06.024.

Baird, J.A., Van Eerdenbrugh, B., Taylor, L.S., 2010. A classification system to assess the crystallization tendency of organic molecules from undercooled melts. J. Pharm. Sci. 99 (9), 3787-3806. doi:10.1002/jps.22197.

Becker, K., Salar-Behzadi, S., Zimmer, A., 2015. Solvent-free melting techniques for the preparation of lipid-based solid oral formulations. Pharm. Res. 32 (5), 1519-1545. doi:10.1007/s11095-015-1661-y.

Brostow, W., Chiu, R., Kalogeras, I.M., Vassilikou-Dova, A., 2008. Prediction of glass transition temperatures: Binary blends and copolymers. Mater. Lett. 62 (17-18), 3152-3155. doi:10.1016/j.matlet.2008.02.008.

CHMP, \& EMA, 2014. CHMP assessment report: Imbruvica. Procedure No.: EMEA/H/C/ 003791/0000. Retrieved from https://www.ema.europa.eu/documents/assessmentreport/imbruvica-epar-public-assessment-report_en.pdf.

Forster, A., Hempenstall, J., Tucker, I., Rades, T., 2001. Selection of excipients for melt extrusion with two poorly water-soluble drugs by solubility parameter calculation and thermal analysis. Int. J. Pharm. 226 (1-2), 147-161.

Fulop, I., Gyeresi, A., Kiss, L., Deli, M.A., Croitoru, M.D., Szabo-Revesz, P., Aigner, Z., 2015. Preparation and investigation of mefenamic acid - polyethylene glycol - sucrose ester solid dispersions. Acta Pharm 65 (4), 453-462. doi:10.1515/acph-2015-0035.

Gao, P., Shi, Y., 2012. Characterization of supersaturatable formulations for improved absorption of poorly soluble drugs. AAPS J. 14 (4), 703-713. doi:10.1208/ s12248-012-9389-7.

Ghadi, R., Dand, N., 2017. BCS class IV drugs: Highly notorious candidates for formulation development. J. Control. Release 248, 71-95. doi:10.1016/j.jconrel.2017.01.014.

Gordon, M., Taylor, J.S., 1952. Ideal copolymers and the second-order transitions of synthetic rubbers. i. non-crystalline copolymers. J. Appl. Chem. 2 (9), 493-500. doi:10.1002/jctb.5010020901.

Greenhalgh, D.J., Williams, A.C., Timmins, P., York, P., 1999. Solubility parameters as predictors of miscibility in solid dispersions. J. Pharm. Sci. 88 (11), 1182-1190.

Gupta, S., Kesarla, R., Omri, A., 2013. Formulation strategies to improve the bioavailability of poorly absorbed drugs with special emphasis on self-emulsifying systems 848043-848043. ISRN Pharm. 2013. doi:10.1155/2013/848043.

Hancock, B.C., Shamblin, S.L., Zografi, G., 1995. Molecular mobility of amorphous pharmaceutical solids below their glass transition temperatures. Pharm. Res. 12 (6), 799-806. doi:10.1023/a: 1016292416526.

Heinz, A., Strachan, C.J., Gordon, K.C., Rades, T., 2009. Analysis of solid-state transformations of pharmaceutical compounds using vibrational spectroscopy. J. Pharm. Pharmacol. 61 (8), 971-988. doi:10.1211/jpp/61.08.0001.

Janssens, S., Van den Mooter, G., 2009. Review: physical chemistry of solid dispersions. J. Pharm. Pharmacol. 61 (12), 1571-1586. doi:10.1211/jpp/61.12.0001.

Karagianni, A., Kachrimanis, K., Nikolakakis, I., 2018. Co-amorphous solid dispersions for solubility and absorption improvement of drugs: composition, preparation, characterization and formulations for oral delivery. Pharmaceutics 10 (3). doi:10.3390/ pharmaceutics10030098.

Kianfar, F., Ayensu, I., Boateng, J.S., 2014. Development and physico-mechanical characterization of carrageenan and poloxamer-based lyophilized matrix as a potential buccal drug delivery system. Drug Dev. Ind. Pharm. 40 (3), 361-369. doi:10.3109/ 03639045.2012 .762655

Lakshman, J.P., Cao, Y., Kowalski, J., Serajuddin, A.T., 2008. Application of melt extrusion in the development of a physically and chemically stable high-energy amorphous solid dispersion of a poorly water-soluble drug. Mol. Pharm. 5 (6), 994-1002. doi:10.1021/ mp8001073.

Lang, B., McGinity, J.W., Williams, R.O., 3rd., 2014. Hot-melt extrusion-basic principles and pharmaceutical applications. Drug Dev. Ind. Pharm. 40 (9), 1133-1155. doi:10.3109/03639045.2013.838577.

Lin, X., Hu, Y., Liu, L., Su, L., Li, N., Yu, J., Yang, Z., 2018. Physical stability of amorphous solid dispersions: a physicochemical perspective with thermodynamic, kinetic and environmental aspects. Pharm. Res. 35 (6), 125. doi:10.1007/s11095-018-2408-3.

Liu, J., Cao, F., Zhang, C., Ping, Q., 2013. Use of polymer combinations in the preparation of solid dispersions of a thermally unstable drug by hot-melt extrusion. Acta Pharm. Sin. B 3 (4), 263-272. doi:10.1016/j.apsb.2013.06.007.

Lu, M., Guo, Z., Li, Y., Pang, H., Lin, L., Liu, X., Wu, C., 2014. Application of hot melt extrusion for poorly water-soluble drugs: limitations, advances and future prospects. Curr. Pharm. Des. 20 (3), 369-387.

Meng, F., Gala, U., Chauhan, H., 2015. Classification of solid dispersions: correlation to (i) stability and solubility (ii) preparation and characterization techniques. Drug Dev. Ind. Pharm. 41 (9), 1401-1415. doi:10.3109/03639045.2015.1018274.
Miller, D.A., McConville, J.T., Yang, W., Williams, R.O., 3rd, McGinity, J.W., 2007. Hot-melt extrusion for enhanced delivery of drug particles. J. Pharm. Sci. 96 (2) 361-376. doi:10.1002/jps.20806.

National Center for Biotechnology Information, \& Medicine, U. S. N. L. o. PubChem: Compound Summary for CID 24821094 (Ibrutinib). Retrieved 8 Jan 2019 https:// pubchem.ncbi.nlm.nih.gov/compound/24821094\#section = Top.

Novakovic, D., Isomaki, A., Pleunis, B., Fraser-Miller, S.J., Peltonen, L., Laaksonen, T., Strachan, C.J., 2018. Understanding dissolution and crystallization with imaging: a surface point of view. Mol. Pharm. 15 (11), 5361-5373. doi:10.1021/ acs.molpharmaceut.8b00840.

Pharmacyclics, \& LLC. (Revision: 08/2018). Full Prescribing Information: Imbruvica ${ }^{\circledR}$. Retrieved from https://www.imbruvica.com/docs/librariesprovider7/default-documentlibrary/prescribing-information.pdf.

Pina, M.F., Zhao, M., Pinto, J.F., Sousa, J.J., Craig, D.Q.M., 2014. The influence of drug physical state on the dissolution enhancement of solid dispersions prepared via hot-melt extrusion: a case study using olanzapine. J. Pharm. Sci. 103 (4), 1214-1223. doi:10.1002/jps.23894.

Repka, M.A., Bandari, S., Kallakunta, V.R., Vo, A.Q., McFall, H., Pimparade, M.B., Bhagurkar, A.M., 2018. Melt extrusion with poorly soluble drugs - an integrated review. Int. J. Pharm. 535 (1-2), 68-85. doi:10.1016/j.ijpharm.2017.10.056.

Repka, M.A., Shah, S., Lu, J., Maddineni, S., Morott, J., Patwardhan, K., Mohammed, N.N., 2012. Melt extrusion: process to product. Exp. Opin. Drug Deliv. 9 (1), 105-125. doi:10.1517/17425247.2012.642365.

Sarode, A.L., Sandhu, H., Shah, N., Malick, W., Zia, H., 2013. Hot melt extrusion for amorphous solid dispersions: temperature and moisture activated drug-polymer interactions for enhanced stability. Mol. Pharm. 10 (10), 3665-3675. doi:10.1021/ mp400165b.

Sathisaran, I., Dalvi, S.V., 2018. Engineering cocrystals of poorlywater-soluble drugs to enhance dissolution in aqueous medium. Pharmaceutics 10 (3), 108. doi:10.3390/ pharmaceutics10030108.

Shah, N., Sandhu, H., Choi, D.S., Chokshi, H., Malick, A.W., 2014. Amorphous Solid Dispersions: Theory and Practice. Springer, New York.

Shah, S., Maddineni, S., Lu, J., Repka, M.A., 2013. Melt extrusion with poorly soluble drugs. Int. J. Pharm. 453 (1), 233-252. doi:10.1016/j.ijpharm.2012.11.001.

Shi, X., Song, S., Ding, Z., Fan, B., Huang, W., Xu, T., 2019. Improving the solubility, dissolution, and bioavailability of ibrutinib by preparing it in a coamorphous state with saccharin. J. Pharm. Sci. 108 (9), 3020-3028. doi:10.1016/j.xphs.2019.04.031.

Simões, M.F., Pereira, A., Cardoso, S., Cadonau, S., Werner, K., Pinto, R.M.A., Simões, S., 2019. A 5-stage approach for a systematic screening and development of etravirine amorphous solid dispersions by hot-melt extrusion. Mol. Pharm. doi:10.1021/ acs.molpharmaceut.9b00996.

Simoes, M.F., Pinto, R.M.A., Simoes, S., 2019. Hot-melt extrusion in the pharmaceutical industry: toward filing a new drug application. [Review]. Drug Discov. Today 24 (9), 1749-1768. doi:10.1016/j.drudis.2019.05.013.

Skrdla, P.J., Floyd, P.D., Dell'Orco, P.C., 2019. Predicting the solubility enhancement of amorphous drugs and related phenomena using basic thermodynamic principles and semi-empirical kinetic models. Int. J. Pharm. 567, 118465. doi:10.1016/ j.ijpharm.2019.118465

Stankovic, M., Frijlink, H.W., Hinrichs, W.L., 2015. Polymeric formulations for drug release prepared by hot melt extrusion: application and characterization. Drug Discov. Today 20 (7), 812-823. doi:10.1016/j.drudis.2015.01.012.

Tran, P., Pyo, Y.-C., Kim, D.-H., Lee, S.-E., Kim, J.-K., Park, J.-S., 2019. Overview of the manufacturing methods of solid dispersion technology for improving the solubility of poorly water-soluble drugs and application to anticancer drugs. Pharmaceutics 11 (3), 132. doi:10.3390/pharmaceutics11030132.

Trivino, A., Gumireddy, A., Meng, F., Prasad, D., Chauhan, H., 2019. Drug-polymer miscibility, interactions, and precipitation inhibition studies for the development of amorphous solid dispersions for the poorly soluble anticancer drug flutamide. Drug Dev. Ind. Pharm. 1-15. doi:10.1080/03639045.2019.1606822.

Van Krevelen, D.W., Te Nijenhuis, K., 2009. Chapter 7 - Cohesive Properties and Solubility. In: Properties of Polymers, fourth ed. Elsevier, Amsterdam, pp. 189-227.

Wang, J.-S., Porter, R.S., 1995. On the viscosity-temperature behavior of polymer melts. Rheol. Acta 34 (5), 496-503. doi:10.1007/bf00396562.

Yoshioka, M., Hancock, B.C., Zografi, G., 1995. Inhibition of indomethacin crystallization in poly(vinylpyrrolidone) coprecipitates. J. Pharm. Sci. 84 (8), 983-986.

Zvoníček, V., Skořepová, E., Dušek, M., Babor, M., Žvátora, P., Šoóš, M., 2017. First crystal structures of pharmaceutical ibrutinib: systematic solvate screening and characterization. Cryst. Growth Des. 17 (6), 3116-3127. doi:10.1021/acs.cgd.7b00047.

Zvoníček, V., Skořepová, E., Dušek, M., Žvátora, P., Šoóš, M., 2018. Ibrutinib polymorphs: crystallographic study. Cryst. Growth Des. 18 (3), 1315-1326. doi:10.1021/ acs.cgd.7b00923. 